\title{
A FINE STRUCTURAL MODIFICATION OF GLYCOSAMINOGLYCANS IS CORRELATED WITH THE PROGRESSION OF MUSCLE REGENERATION AFTER ISCHAEMIA: TOWARDS A MATRIX-BASED THERAPY?
}

\author{
F. Chevalier ${ }^{1,3}$, D. Arnaud ${ }^{2, \S}$, E. Henault ${ }^{1, \S}$, O. Guillevic ${ }^{3}$, F. Siñeriz ${ }^{4}$, A-C. Ponsen ${ }^{3}$, D. Papy-Garcia ${ }^{1}$, D. Barritault ${ }^{4}$, \\ D. Letourneur ${ }^{2}$, G. Uzan ${ }^{3}$, A. Meddahi-Pellé ${ }^{2}$, H. Hlawaty ${ }^{2}$ and P. Albanese ${ }^{1, *}$ \\ ${ }^{1}$ Laboratoire Croissance, Régénération, Réparation et Régénération Tissulaires (CRRET)/ EAC CNRS 7149, \\ Université Paris Est Créteil, Université Paris Est, 94010, Créteil, France. \\ ${ }^{2}$ INSERM, U1148, Université Paris 13, Sorbonne Paris Cité, Paris, France \\ ${ }^{3}$ INSERM, U972, Paul Brousse Hospital, Villejuif, France \\ ${ }^{4}$ OTR3 Company, 4 rue Française, 75001 Paris, France
}

§These authors contributed equally to this work.

\begin{abstract}
Critical limb ischaemia often leads to amputation of the limb and potential mortality. Moreover, there are still significant problems with current therapeutic treatments, according to poor revascularisation of degenerated tissue probably due to modifications within the microenvironment. This study is focused on the changes of structure and bioactivity of glycosaminoglycans (GAGs), especially heparan sulphate (HS) and chondroitin sulphate (CS) in rat Extensor Digitorum Longus (EDL) muscle after ischaemia. Male Wistar rats were subjected to ischaemic-injury by ligation of the neurovascular trunk accompanying EDL-tendon. After 4, 8, 15, 21, 60 and $90 \mathrm{~d}$, the rats were sacrificed and the muscles were collected and submitted to histological, biochemical and gene expression assays. We demonstrated that ischaemia induced modification of expression of enzymes involved in GAG biosynthesis which correlated with significant changes in HS and CS structural features such as size and sulphation pattern. These major structural changes are associated to modifications of GAG abilities to bind growth factors and to modulate cell activity. Moreover, a CS hallmark of injury is maintained as well after the regeneration process. Finally, we showed the relevance of the role of this glycanic matrix remodelling, since a GAG mimetic treatment accelerated muscle repair after ischaemia.
\end{abstract}

Keywords: Glycosaminoglycan, ischaemia, tissue remodelling, skeletal muscle, angiogenesis, matrix therapy.

*Address for correspondence:

Patricia Albanese, $\mathrm{PhD}$

Université Paris Est Créteil, Faculté des Sciences et Technologie, CRRET Laboratory

61 avenue du Général de Gaulle

94010 Créteil cedex, France

Telephone Number: $(+33) 1.45 .17 .14 .05$

FAX Number: $(+33) 1.45 .17 .18 .16$

E-mail address: albanese@u-pec.fr

\section{Introduction}

Peripheral artery disease (PAD) refers to dysfunction of the blood vessels located outside the heart and brain, resulting in blood flow decrease to the legs. Critical limb ischaemia (CLI) is the most advanced form of PAD, often leading to amputation of the limb and potential mortality despite surgical therapies (Berger and Hiatt, 2012; Sobieszczyk and Eisenhauer, 2013). Recently, clinical trials using cell therapy have demonstrated promising results (Raval and Losordo, 2013). But there are still significant problems with poor cell retention and survival (Goussetis et al., 2006; Terrovitis et al., 2009; Zeng et al., 2007). This is probably due to high expression of inflammatory mediators and degradation of pro-survival or proliferating factors (Desouza et al., 2011; Suzuki et al., 2004; Verma et al., 2004). This underlines the relevance to better knowing the microenvironment on which therapeutic strategies are performed. Skeletal muscle has the capacity to repair in response to injury, according to a complex homeostatic process that occurs in four interrelated and time-dependent phases: degeneration, inflammation, regeneration and tissue remodelling (Crisco et al., 1994). A better understanding of all of these regulated steps should allow optimising therapeutic strategies. It is well known that multiple cell populations and numerous cytokines and growth factors, released from injured tissue, are involved in the progression of the regeneration process. However, little is known about extracellular matrix (ECM) components that play complex roles in cell behaviour to maintain tissue homeostasis. Among them, glycosaminoglycans (GAGs) are long anionic polysaccharides composed by specific disaccharide building blocks. The structure of GAGs is highly complex due to heterogeneity in glycosidic linkage, sulphation pattern and hydrophobic regions regulating their interactions with surrounding molecules. Four GAG subfamilies are distinguished through their repeating disaccharide units: heparan sulphate (HS), chondroitin sulphate (CS), keratan sulphate and hyaluronic acid (HA). Sulphated GAGs are covalently linked to a core protein to form proteoglycans (PGs) whereas HA, which is the only unsulphated GAG, is free in the ECM. PGs and $\mathrm{HA}$ interact with proteins to strengthen the structure and equilibrium of the ECM. However, it is now accepted that GAGs also have functional roles, related to their particular structural characteristics, since they protect and trigger the 
activity of heparin-binding proteins (HBPs), which include chemokines, cytokines and enzymes (Gandhi and Mancera, 2008). Sulphated GAGs thus provide matrix-bound or cell surface-bound reservoirs for HBPs, protecting them from proteolytic degradation, increasing their half-life and providing storage sites (Friedl et al., 1997; Handel et al., 2005). Moreover, by immobilising HBPs on the ECM and cell surfaces, GAGs restrain their diffusion and facilitate both the formation of local gradients and the synchronous coordination of motility and cell adhesion (Campbell et al., 1998; Lortat-Jacob, 2009; Schumann et al., 2010). Whereas many studies focus on PGs syndecan 3 and 4 roles during muscle regeneration (Casar et al., 2004; Cornelison et al., 2001; Matsui et al., 2011), few data are available on the effect of GAG chain remodelling. Indeed, after tissue injury, the dying cells release enzymes degrading GAGs. This induces a massive liberation of HBPs that are no longer protected by GAGs, leading to their rapid degradation. In this way, we have developed techniques that permit extensive study of structural and functional glycan features. We recently demonstrated that the fine structure of GAGs and their capacities to regulate trophic factor activities are modified during physiological processes such as aging (Huynh et al., 2012a; Huynh et al., 2012b). Since the role of GAGs in tissue homeostasis is only emerging, we investigate here how endogenous GAGs, especially HS and CS species, would be structurally and functionally modified over time after ischaemia and the subsequent regeneration process. According to such interest, we previously developed a family of chemically engineered polymers mimicking the structure of the natural GAGs (Papy-Garcia et al., 2005). These compounds functionally replace the endogenous GAGs after tissue injury, since they are resistant to glycanase degradation and thus improve HBPs protection and function during matrix remodelling (Meddahi et al., 2002; Meddahi et al., 1995). Their regenerative effect was already described in various preclinical models (Desgranges et al., 1999; Garcia-Filipe et al., 2007; Lallam-Laroye et al., 2006; Yamauchi et al., 2000) and some compounds of this family are currently used in clinics for the treatment of chronic ulcers. Hence, in order to give in vivo evidence of the importance of the glycanic matrix remodelling in tissue homeostasis, we validated a first proof of concept that a GAG mimetic treatment can accelerate muscle repair after ischaemia.

\section{Materials and Methods}

\section{Experimental model of critical hindlimb ischaemia}

Male Wistar rats (Janvier, CERJ, Laval, France) weighing 280-300 g and aged 8 weeks were anaesthetised with $50 \mathrm{mg} / \mathrm{kg}$ sodium pentobarbital (CEVA Santé Animal, Libourne, France). The surgical procedure was already described elsewhere (Desgranges et al., 1999) and was approved for this study by the Bichat University Institutional Animal Care and Use Committee ( $\mathrm{N}^{\circ} 2011$ 14/698-0038). To summarise, the total blockage of perfusion of the left Extensor Digitorum Longus (EDL) muscle was based on the section of the neurovascular trunk at the EDL entry and completed by ligation (without cutting) of both proximal and distal tendons (surgical suture 4-0, Ethicon, Norderstedt, Germany). The tendon ligation was maintained until the end of study and total scraping with a forceps of blood vessels accompanying both tendons $\left(\mathrm{EDL}_{\text {isch }}\right)$ was performed to avoid blood irrigation, directly on the muscle (microvascularisation from proximal to distal tendon) and in the nerve environment. The right EDL of the same rat was exposed and used as a non-ischaemic control (EDL normal $_{\text {) }}$ ).

To determine the predictive value of the occlusion pattern after ischaemia, Magnetic Resonance Imaging (MRI), Time-Of-Flight Angiography with maximum intensity projection $3 \mathrm{D}$ reconstruction (3D-TOF Angiography) and Intravital Fluorescence Microscopy (IFM) were performed in the $\mathrm{EDL}_{\text {normal }}$ group and $\mathrm{EDL}_{\text {isch }}$ group. The MRI and 3D-TOF Angiography (Bruker's Pharma Scan ${ }^{\circledR}$ MR Scanner, actively shielded magnets at 7T; Bruker, The Woodlands, TX, USA) was used following isoflurane anaesthesia $30 \mathrm{~min}$ after EDL injury. The IFM was performed using fluorescent microscopy $30 \mathrm{~min}$ after EDL injury and following fluorescein isothiocyanatelabelled dextran (FITC-dextran) intravascular injection.

To establish the complete time course of $\mathrm{EDL}_{\text {isch }}$ muscle regeneration, rats were euthanised by an overdose of sodium pentobarbital according to a time-spanning from day $0(n=18)$ to days $4,8,15,21$ ( $n=18$ per time point), $60(n=9)$ and $90(n=6)$ after ischaemia. Muscle samples were treated for immuno-histological studies and GAG characterisation as described below and compared to the same number of normal (healthy or contralateral) EDL rat muscle $\left(\mathrm{EDL}_{\text {normal }}\right)$.

\section{GAG mimetic treatment}

The $\left[\mathrm{OTR}_{4131}\right]$ GAG mimetic (OTR3 Company, Paris, France) is a chemically engineered sulphated dextran derivative polymer. It is composed of about 250 glycosidic units, presents degrees of substitution of carboxylate and sulphate residues comparable to HS, differing from this in the acetyl group ratio (Mangoni et al., 2009). To evaluate its effect, $100 \mu \mathrm{L}$ of $10 \mu \mathrm{g} / \mathrm{mL}\left[\mathrm{OTR}_{4131}\right]$ solution $\left(\mathrm{EDL}_{\text {isch }+ \text { OTR }}\right)$ was injected in ischaemic muscle immediately after surgery and compared to saline-treated ischaemic EDL $\left(\mathrm{EDL}_{\text {isch }}\right.$, placebo group) and to normal healthy/contralateral EDL (EDL $\mathrm{E}_{\text {normal }}$, control group). Rats were euthanised after 4 or $8 \mathrm{~d}(n=3$ per treatment and per day) corresponding, respectively, to inflammatory and to angiogenesis peaks. This experiment was performed three times independently.

\section{Histological and morphological analysis}

EDL muscles were embedded in Tissue-Tek OCT Compound (Tissue-Tek, Hatfield, PA, USA), frozen in liquid nitrogen and kept at $-80{ }^{\circ} \mathrm{C}$ to conserve an intact morphology. For tissue analysis, all muscles were manipulated and sectioned at $-20{ }^{\circ} \mathrm{C}$. The transversally thick cross-section with $10 \mu \mathrm{m}$ were performed in the central and largest part of EDL muscle $(\sim 3 \mathrm{~mm}$ diameter, $10 \mathrm{~mm}^{2}$ surface) using a cryostat as previously described (Desgranges et al., 1999). Then, the thick cross-sections were stained with haematoxylin/eosin for topographical examination. Digital-slides were acquired and analysed with a NanoZoomer ${ }^{\circledR}$ (Hammatsu, Hamamatsu City, 
Japan). Additional sections were stained with $1 \%$ lugol substrate (Merck Millipore, Darmstadt, Germany) to study phosphorylase activity, indicating metabolic status of skeletal muscle fibres (brown stain: glycogenolysis; yellow stain: no metabolic activity) (Carlson and Gutmann, 1975). Then, the architecture of muscle fibres with quantification of the nuclei with peripheral and central localisation has been analysed in different groups using high view images. Quantification of activated and mature muscle fibres, with central and peripheral nuclei respectively, was performed and normalised by $1 \mathrm{~mm}^{2}$ surface of muscle for each group.

To evaluate angiogenesis, the total number of microvessels $(\mathrm{N})$ on muscle cross-sections was determined according to double positive immunostaining for CD31 (unconjugated; BD Biosciences, Le Pont de Claix, France) and $\alpha$-SMA (coupled to Cyanine 3; Sigma-Aldrich, Saint-Quentin-Fallavier, France). Unconjugated antiCD31 was further detected with a secondary antibody conjugated with Alexa Fluor ${ }^{\circledR} 488$ dye (Invitrogen, Cergy Pontoise, France). Then, the sections were processed with Glycergel $^{\circledR}$ mounting medium (DAKO, Trappes, France) and DAPI according to the manufacturer's instructions. Immunofluorescence was visualised with a fluorescence microscope $(200 \times$ magnification). Digital images were collected with a Leica camera (Leica, Wetzlar, Germany) interfaced with the Metaview software. All microvessels were quantified in the total surface $\left(\mathrm{mm}^{2}\right)$ of muscle crosssection leading to the analysis of vessel density ( $\mathrm{N}$-number $/ \mathrm{mm}^{2}$-muscle cross-section surface). These quantitative analyses were performed on 3 independent experiments, analysed according to ANOVA/ANCOVA statistic tests using Stat View software $(n=9, * p<0.05)$.

\section{GAGs extraction and quantification}

Frozen EDL muscles were freeze-dried and suspended in extraction buffer for further GAG extraction as previously described (Huynh et al., 2012a), according to slight modifications. Briefly, samples were digested by proteinase K (Merck Millipore) and DNase (Qiagen, Hilden, Germany) and then transferred to $4 \mathrm{~mol} / \mathrm{L} \mathrm{NaCl}$ final sample concentration and vigorously agitated for $30 \mathrm{~min}$. Proteins were precipitated and supernatants were cleared by chloroform washing followed by dialysis (Spectrum, Breda, The Netherlands) of the aqueous phase against extraction buffer and then pure water. After freeze drying, species of the extracted GAGs were analysed by specific digestion with chondroitinase ABC (Sigma-Aldrich, SaintQuentin-Fallavier, France) or by nitrous acid treatment and quantified according to the 1,9-dimethyl-methylene blue (DMMB) assay as previously described (Barbosa et al., 2003).

\section{Structural characterisation of GAGs}

In order to follow the size of the GAG chains along the time course after ischaemia, $5 \mu \mathrm{g}$ of extracted GAGs and a HA ladder (Sigma-Aldrich) were loaded in a $2 \%$ agarose gel and run in TAE $1 \mathrm{X}$ buffer for $150 \mathrm{~min}$ at $50 \mathrm{mV}$. After migration, the plate was stained with $0.005 \%$ StainsAll solution (Sigma-Aldrich) overnight in the dark and destained with water. In addition, an HPLC-Size Exclusion Chromatographic (SEC) technique allows GAG mass distribution determination in a more quantitative way through absorbance detection of the complexes formed between copper ions and carboxylate GAG groups (Toida et al., 1997). Briefly, $5 \mu \mathrm{g}$ of purified HS or CS samples in $90 \mu \mathrm{L} \mathrm{H}_{2} \mathrm{O}$ were eluted at $0.8 \mathrm{~mL} / \mathrm{min}$ flow rate with a solution containing $1 \mathrm{mmol} / \mathrm{L} \mathrm{CuSO}_{4} .5 \mathrm{H}_{2} \mathrm{O}$ and $10 \mathrm{mmol} / \mathrm{L}$ $\mathrm{NaCl}$ at pH 5.0 through a Shodex OHpak SB-804-HQ column (Waters, Guyancourt, France) placed at $40{ }^{\circ} \mathrm{C}$. Chromatograms of copper-GAG complexes were recorded after UV detection and peaks of retention time were used to calculate shifts between GAG (HS or CS) extracted from $\mathrm{EDL}_{\text {normal }}$ or $\mathrm{EDL}_{\text {isch }}$. GAG chain length modifications were estimated from these values, according to a standard curve.

Disaccharides of purified HS or CS were obtained by treatment with either a heparinase I, II and III cocktail (AMS Biotechnology, Abingdon, UK; $0.25 \mathrm{mU}$ each, $24 \mathrm{~h}, 37^{\circ} \mathrm{C}$ ) or chondroitinase ABC (Sigma-Aldrich; $20 \mathrm{mU}, 90 \mathrm{~min}, 37^{\circ} \mathrm{C}$ ). Samples were analysed by HPLC as previously described (Toyoda et al., 1999) with some modifications. Briefly, $50 \mu \mathrm{L}$ of sample was loaded onto a Propac PA-1 (Dionex, Amsterdam, The Netherlands) strong-anion exchange column eluted by a $\mathrm{NaCl}$-solvent gradient. Post-column in-line modification was realised by mixing 2 -cyanoacetamide solution $(2 \% \mathrm{v} / \mathrm{v})$ and $250 \mathrm{mmol} / \mathrm{L} \mathrm{NaOH}$, both supplied at $0.25 \mathrm{~mL} / \mathrm{min}$. The mixture passed through a reaction coil set in an oven at $120{ }^{\circ} \mathrm{C}$, followed by a cooling coil and then fluorimetric monitoring was registered $(\lambda=346 \mathrm{~nm}$ excitation, $\lambda=410 \mathrm{~nm}$ emission). Areas under curve were measured and the percentage of each disaccharide in the sample was calculated relative to external standards.

\section{GAG biosynthetic enzyme expression in ischaemic muscle}

Total RNA was extracted from frozen rat $\mathrm{EDL}_{\text {normal }}$ or $\mathrm{EDL}_{\text {isch }}$ muscle using the commercial RNeasy ${ }^{\circledR}$ Fibrous Tissue Midi Kit (Qiagen) according to the provided manufacturer's manuals. Extracted RNA was used to synthesise complementary DNA (cDNA) by a reverse transcriptase reaction with the High Capacity cDNA Reverse Transcription Kit (Applied Biosystems, Life Technologies, Cergy Pontoise, France). The quantitative PCR assays were performed in 96-well plate with TaqMan ${ }^{\circledR}$ Gene Expression Assays (Life Technologies, Cergy Pontoise, France) available on request (see Table 1), in the presence of $40 \mathrm{ng}$ of cDNA per well, with Stratagene Mx3500P system (Agilent Technologies, Santa Clara, CA, USA). The quantification levels for gene expression were calculated using the $2^{-\Delta \mathrm{CT}}$ method by normalising to endogenous rat TATA-box binding protein (TBP), used as housekeeping gene.

\section{GAG binding competition towards heparin-binding proteins}

Capacities of GAGs extracted from $\mathrm{EDL}_{\text {normal }}$ and $\mathrm{EDL}_{\text {isch }}$ to bind to human FGF2 and IL8 were evaluated by an ELISA based competition assay as described by Najjam et al. (1997). Briefly, ELISA plates (VWR, Fontenay sous Bois, France) were coated with $0.5 \mu \mathrm{g} /$ well of heparin-BSA complex. After washing ( $1 \times$ PBS $-0.05 \%$ Tween 20), wells were saturated with $3 \%$ BSA in $1 \times$ 
Table 1. Gene name and corresponding Taqman ${ }^{\circledR}$ reference for RTqPCR analysis.

\begin{tabular}{|c|c|c|}
\hline Gene category & Official name/Alias & TaqMan ${ }^{\circledR}$ gene expression assay identity \\
\hline Reference gene & TBP & Rn01455646_m1 \\
\hline \multirow{12}{*}{ Genes involved in HS biosynthesis } & EXT1 & Rn00468764_m1 \\
\hline & EXT2 & Rn01486349_m1 \\
\hline & HS2ST & Rn01522461_m1 \\
\hline & GLCE & $\mathrm{Rn} 01417963 \_\mathrm{m} 1$ \\
\hline & NDST1 & Rn01491301_m1 \\
\hline & NDST2 & $\mathrm{Rn} 01537102 \_\mathrm{m} 1$ \\
\hline & NDST3 & Rn01522603_m1 \\
\hline & NDST4 & $\mathrm{Rn} 01522553 \_\mathrm{m} 1$ \\
\hline & HS6ST1 & $\mathrm{Rn} 01441523$ m1 \\
\hline & HS6ST2 & Rn01457382_m1 \\
\hline & HS6ST3 & Custom Plus Assay ID: AJHSN99 \\
\hline & HSPE & Rn00575080_m1 \\
\hline \multirow{12}{*}{ Genes involved in CS biosynthesis } & CHSY1/CSS1 & $\mathrm{Rn} 01478125 \_\mathrm{m} 1$ \\
\hline & CHPF/CSS2 & Rn01400270_m1 \\
\hline & UST & $\mathrm{Rn} 01766117 \mathrm{~m} 1$ \\
\hline & DSE & Rn02109126_s1 \\
\hline & CHST11/C4ST1 & Rn01509313_m1 \\
\hline & CHST12/C4ST2 & Rn02606748_s1 \\
\hline & CHST13/C4ST3 & Rn02606748_s1 \\
\hline & CHST14/D4ST1 & Rn01747177_s1 \\
\hline & CHST3/C6ST1 & Rn00584637_m1 \\
\hline & CHST7/C6ST2 & Rn01430599_m1 \\
\hline & CHST15 & Rn00597859_m1 \\
\hline & HYAL4/CSHY & $\mathrm{Rn} 01456029 \_\mathrm{m} 1$ \\
\hline \multirow{4}{*}{ Genes involved in HA biosynthesis } & HAS1 & Rn01455687_g1 \\
\hline & HAS2 & $\mathrm{Rn} 00565774 \_\mathrm{m} 1$ \\
\hline & HAS3 & Rn01643950_m1 \\
\hline & HYAL2 & Rn01521340_g1 \\
\hline \multirow{5}{*}{ Others } & IL6 & Rn01410330_m1 \\
\hline & IL10 & Rn00563409_m1 \\
\hline & FADD & Rn00596168_m1 \\
\hline & MYH2 & $\mathrm{Rn} 01470656 \_\mathrm{m} 1$ \\
\hline & MYOG & Rn01490689_g1 \\
\hline
\end{tabular}

PBS. Then, HBPs (FGF2: 0.5 ng/well; IL8: 20 ng/well) and increasing concentration of extracted GAGs $(0,0.1$, $1,10,100,1000$ and $10000 \mathrm{ng} / \mathrm{mL}$ in $1 \times$ PBS) were simultaneously added into duplicate wells. After $1 \mathrm{~h}$ of binding competition, the protein remaining bound to heparin was targeted by a corresponding specific antibody (anti-FGF2, R\&D Systems, Abingdon, UK; anti-IL8, Promokine, Heidelberg, Germany) followed by a HRPconjugated secondary antibody (Interchim, Montluçon, France). Resulting peroxidase activity was measured by the oxidation of 3,3',5,5'-tetramethylbenzidine (TMB; Thermo Scientific, Illkirch, France) substrate as described by the manufacturer's protocol. The maximum binding value was determined in the absence of extracted GAGs and was used as a reference to determine the dose sufficient to displace $50 \%$ of binding of HBPs to immobilised heparin $\left(\mathrm{IC}_{50}\right)$. Finally, $\mathrm{IC}_{50}$ values were normalised for each $\mathrm{HBP}$ to the $\mathrm{IC}_{50}$ of GAGs extracted from $\mathrm{EDL}_{\text {normal }}\left(\mathrm{IC}_{50}\right.$ reference $\left.=1\right)$.

\section{Effect of GAGs on BaF32 cell mitogenic activity}

BaF32 cells were maintained in RPMI medium supplemented with $10 \%$ horse serum and $1 \mathrm{ng} / \mathrm{mL}$ IL3, as previously described (Ornitz et al., 1992). For the assay, cells were seeded into 96-well plates at a density of 500,000 cells/well in RPMI-10 \% horse serum with $50 \mathrm{ng} / \mathrm{mL} \mathrm{FGF2}$ and $1 \mu \mathrm{g} / \mathrm{mL}$ of the extracted GAGs (final concentration). After $72 \mathrm{~h}$ incubation at $37^{\circ} \mathrm{C}$, propidium iodide-negative living cells were counted by flow cytometry (MACS Quant; Miltenyi Biotech, Paris, France). Results were normalised to the number of living cells in the PBS condition.

\section{Cytokine quantification in ischaemic tissue}

At day 4 post-surgery $\mathrm{EDL}_{\text {normal }}, \mathrm{EDL}_{\text {isch }}$ or $\mathrm{EDL}_{\text {isch }+\mathrm{OTR}}$ muscles were harvested, rinsed with $1 \times$ PBS and incubated for $24 \mathrm{~h}$ in $0.5 \mathrm{~mL}$ of RPMI serum free media (Kochtebane et al., 2013). Supernatants were analysed for Vascular Endothelial Growth Factor (VEGF) and interleukin 10 (IL10) using cytokine/chemiokine analysis kits based on the Luminex MPA technology (MILLIPLEX MAP Kit, Rat Cytokine/Chemiokines Magnetic Bead Panel, $\mathrm{N}^{\circ}$ RECYTMAG-65K; Merck Millipore) on the BioPlex 200 (Bio Rad, Marnes-la-Coquette, France). The samples were analysed followed the manufacturer's recommendations. 
(a)
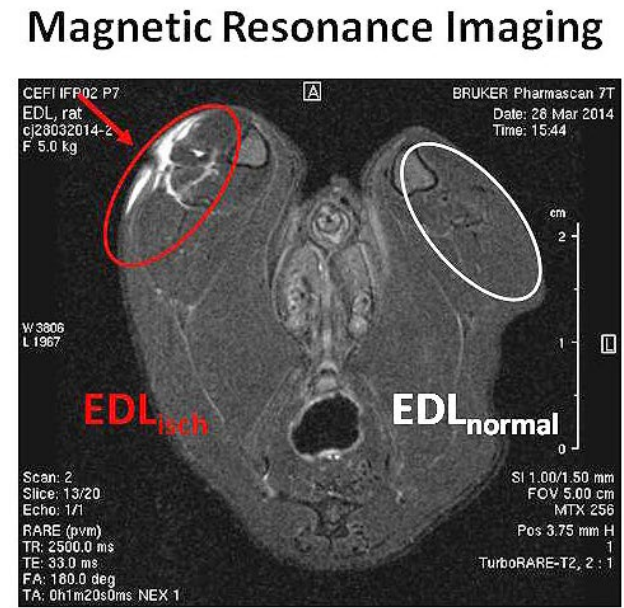

3D-TOF Angiography

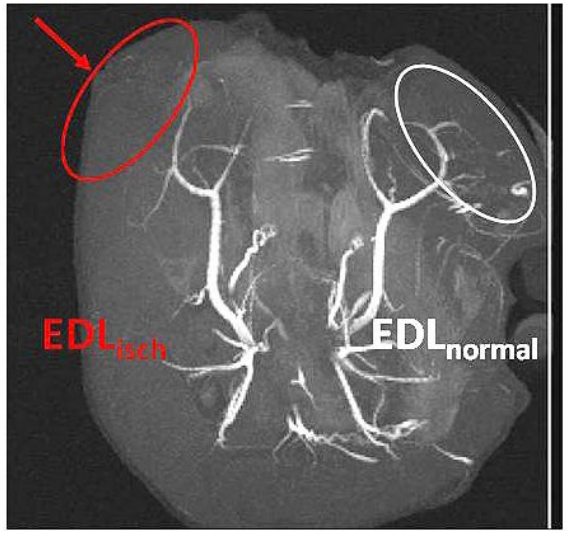

(b)

\section{Intravital fluorescence microscopy}
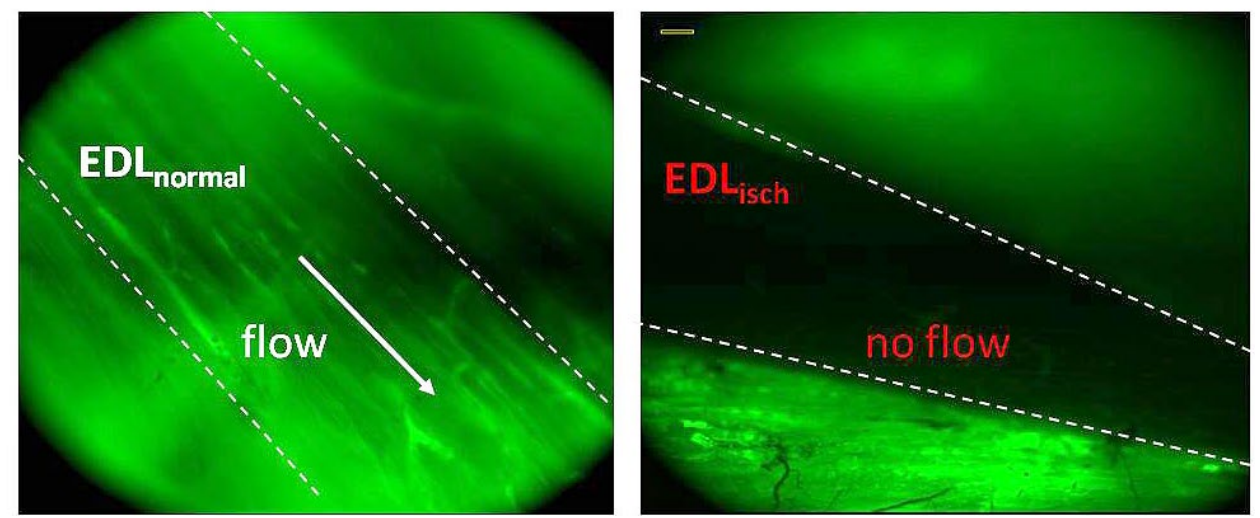

Fig. 1. Angiogram before and after ischaemia injury in EDL muscle. MRI (a, left) detected a hypersignal intensity (red circle and arrow) in $\mathrm{T} 2$ weighted imaging showing the presence of an oedema in $\mathrm{EDL}_{\text {isch }}$ not detected in $\mathrm{EDL}_{\text {normal }}$ (white circle and arrow). 3D-TOF angiography (a, right) confirmed a decreased number of vessels in $\mathrm{EDL}_{\text {isch }}$ (red circle and arrow) as compared to $\mathrm{EDL}_{\text {normal }}$ (white circle and arrow). Intravital fluorescence microscopy (b, left) showed normal blood circulation in $\mathrm{EDL}_{\text {normal }}$. Arrow indicates the direction of blood flow. The vessels are highlighted in white dotted line. The absence of fluorescent signal in $\operatorname{EDL}_{\text {isch }}(\mathbf{b}$, right $)$ indicated the absence of blood flow $(n=3$ for each experiment). All analyses were performed 30 min after injury.

\section{Statistical Analysis}

Data are expressed as mean \pm SEM. Difference statistically significant was determined with one way ANOVA analysis followed by the Dunnett post-test when there were more than two groups. For analysis between two groups Student- $t$ test was used.

\section{Results}

\section{Vascular occlusion after ischaemia injury}

The Magnetic Resonance Imaging (MRI, Fig. 1a, left image) and Time-Of-Flight Angiography with maximum intensity projection $3 \mathrm{D}$ reconstruction (3D-TOF Angiography, Fig. 1a, right image) and the Intravital Fluorescence Microscopy (IFM, Fig. 1b) were performed to analyse the ischaemic lesion $30 \mathrm{~min}$ after injury. The hypersignal intensity in T2 weighted imaging indicated the presence of an oedema around the left injured $\mathrm{EDL}_{\text {isch }}$ muscle (Fig. 1a, MRI, red circle and arrow) as compared to right non injured $\mathrm{EDL}_{\text {normal }}$ muscle (Fig. 1a, MRI, white circle). The hyposignal intensity in perfusion weighted imaging indicated an absence of perfusion in the left injured $\mathrm{EDL}_{\text {isch }}$ muscle (data not shown). The absence of blood perfusion in the left injured $\mathrm{EDL}_{\text {isch }}$ muscle was related to the pattern of total flow obstruction in EDL segments, as compared to the right $\mathrm{EDL}_{\text {normal }}$ muscle. In addition, the 3D-TOF Angiography showed a decreased number of vessels in this region (Fig. 1a, TOF Angiography, red circle and arrow) as compared to control muscle (white circle). These results confirmed that the surgical procedure used was sufficient to cause an angiography-diffusion and the muscle devascularisation leading to ischaemia injury.

\section{Clinical evolution of muscle architecture and function}

The time course of lesion and repair processes in rat ischaemic EDL $\left(\mathrm{EDL}_{\mathrm{isch}}\right)$ was analysed on the crosssections of the muscles up to $90 \mathrm{~d}$ of post-surgery (Fig. 2). Before the ischaemic injury (day 0 ), the nuclei were present at the periphery of $\mathrm{EDL}_{\text {normal }}$ myofibres (right panel straight arrows). The EDL injury led to muscle degeneration from 

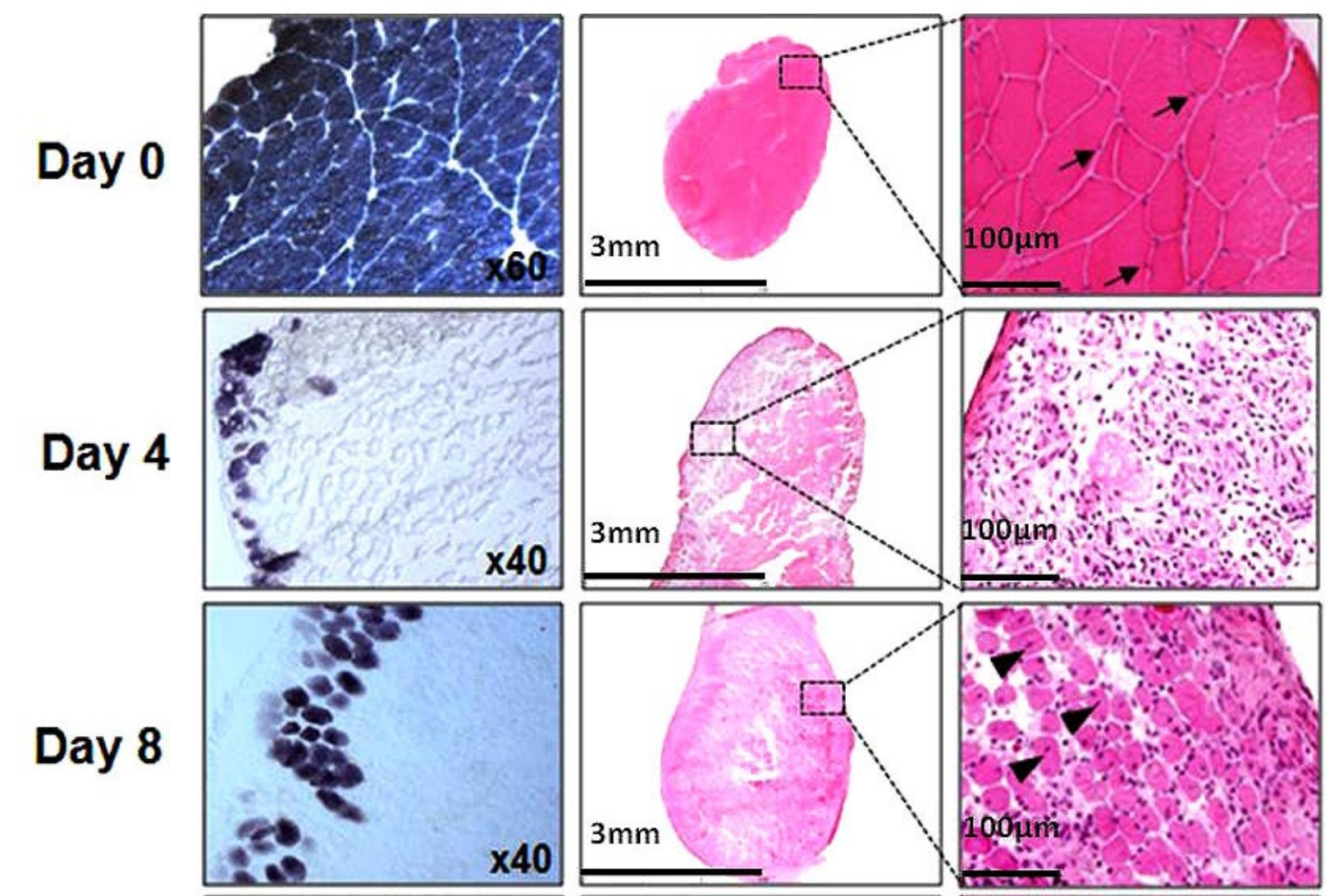

Day 15
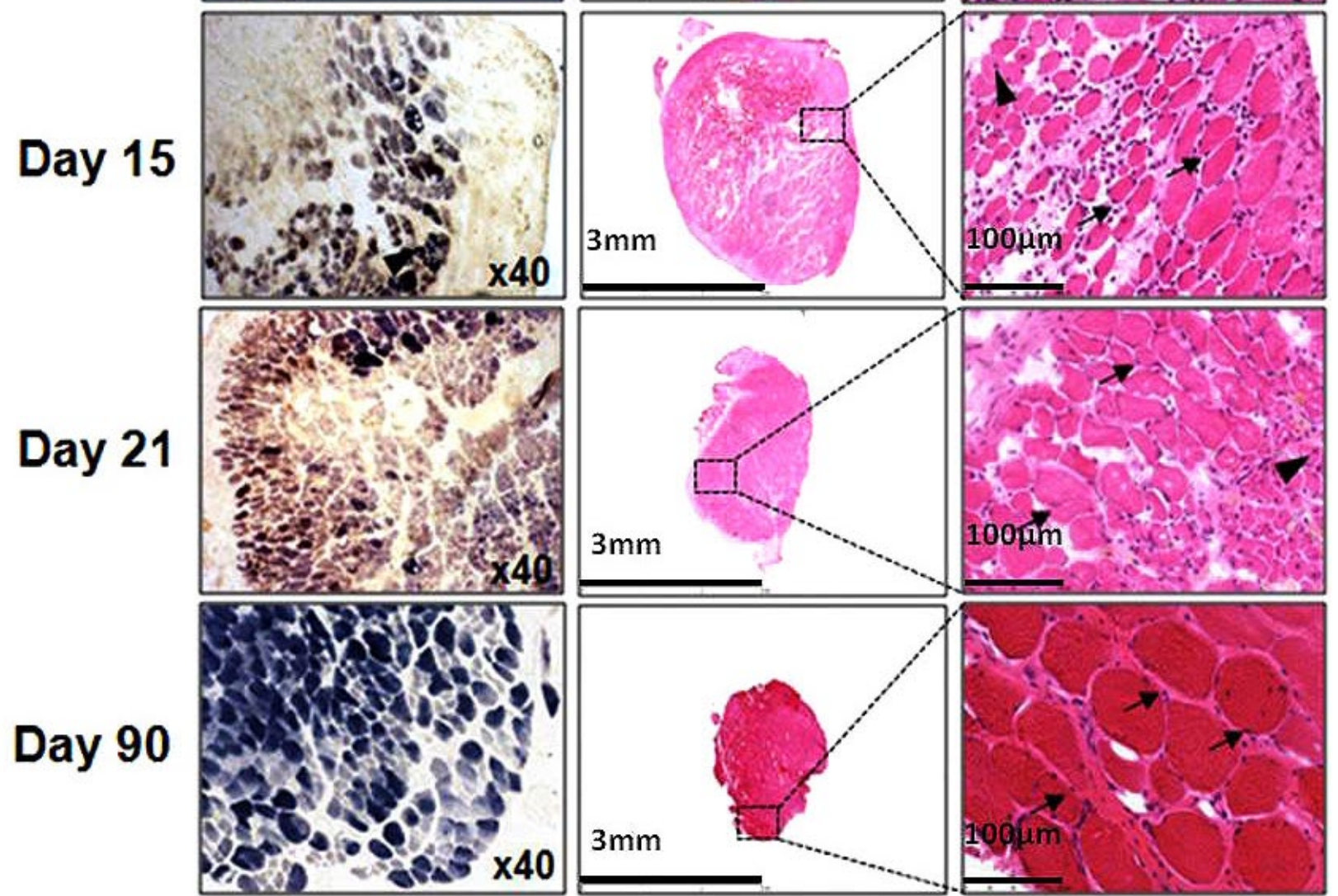

Fig. 2. Morphological studies of ischaemic muscle up to $90 \mathrm{~d}$ of post-surgery. The time course of lesion and regeneration processes in EDL ischaemia was analysed in the muscles cross-sections assessed for phosphorylase activity (left panels, objective: $\times 40$ ) and stained with haematoxylin- eosin (middle panels, scale bar $=3 \mathrm{~mm}$ and right panels, scale bar $=100 \mu \mathrm{m})$. Straight arrows indicate the nuclear localisation in the periphery of the mature cells. Arrowheads indicate the nuclear localisation in the central part of the activated cells. Images were chosen as representative of total cross-section analysis of 6 muscles per group in three independent experiments ( $n=18$ per group). 
Fig. 3. Evolving GAG sulphation levels during rat muscle ischaemia and subsequent regeneration. Sulphation levels of total GAGs (a) and purified CS and HS species (b) extracted from $\mathrm{EDL}_{\text {normal }}$ (day 0) or $\operatorname{EDL}_{\text {isch }}(4,8,15,21,60$ and 90 d) were determined by DMMB assay. Values were normalised on weight of each dried muscle. Sulphation level control corresponds to GAGs extracted from $\mathrm{EDL}_{\text {normal }}$ (dotted lines). Values are the mean and SEM calculated from 12 individual EDL samples in 4 independent experiments for each time point (from day 0 to day $21, n=12$; day 60 , $n=6$; day $90, n=3 ; * p<0.05, * * p<0.01$, $* * * p<0.001)$. (a)

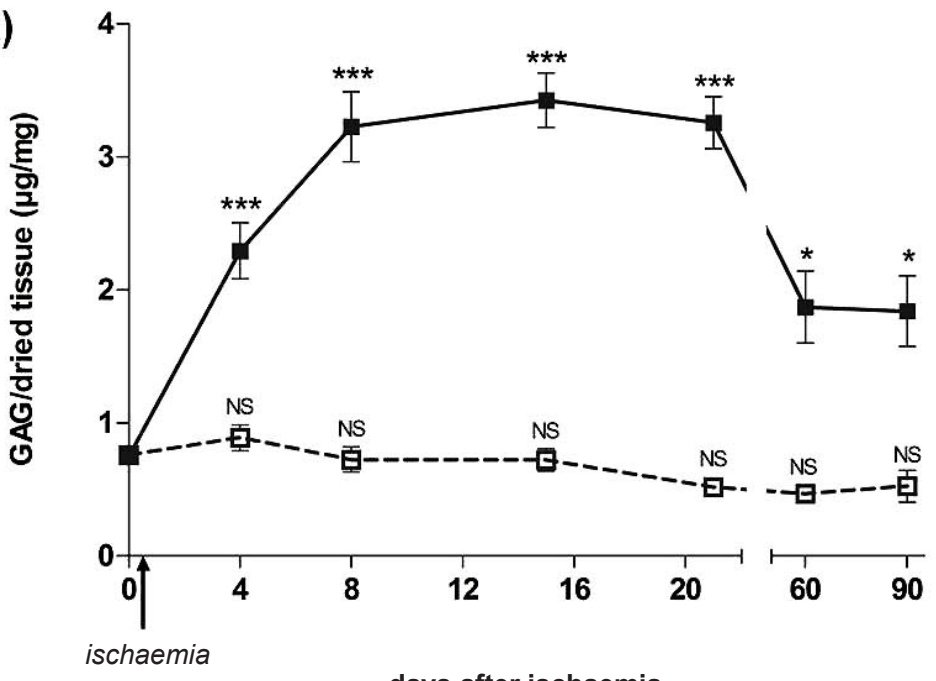

days after ischaemia

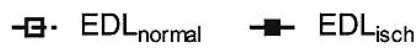

(b)

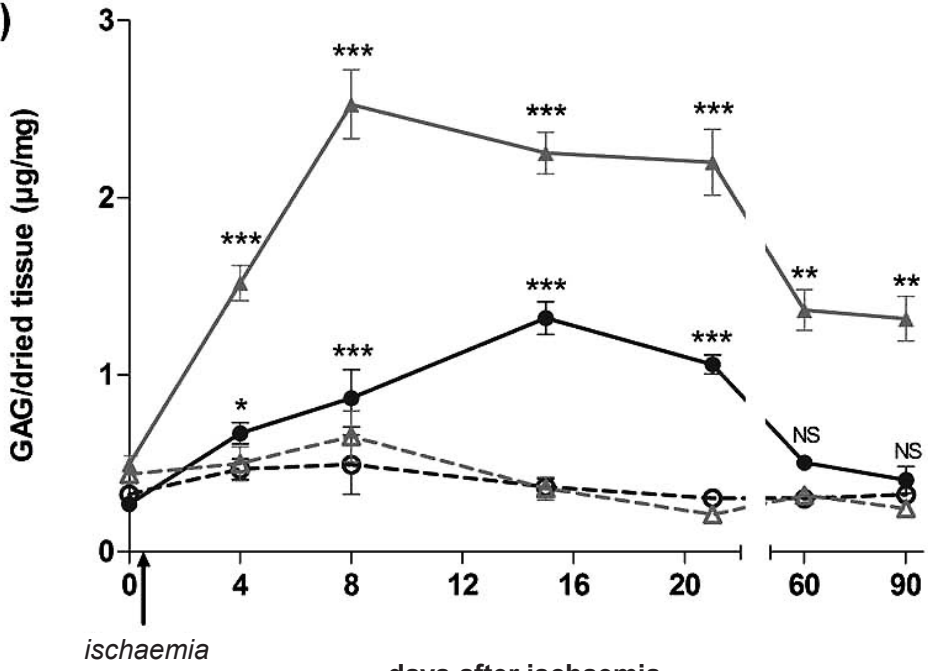

days after ischaemia

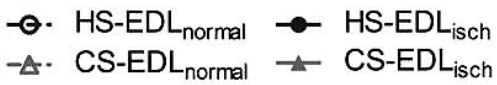

day 4 characterised by a loss of number of myofibres. In addition, the disappearance of the nuclei from the periphery of the myofibres at day 4 evidenced the injury process. The inflammatory cell infiltration appeared in the enlarged endomysium up to day 15 post-surgery. The spontaneous regeneration started at day 8 when the nuclei began to migrate from the centre (right panel arrowheads) to the periphery of myofibres. The evident myofibre maturation was observed from day 15 with numerous nuclei located at the periphery of myofibres (right panel straight arrows). Finally, at day 60 (data not shown) and day 90 the myofibres were well organised, with tight myofibre assembly.

Phosphorylase activity was analysed all along the time course to attest muscle functionality (Fig. 2, left panel). Only few mature cells were still functional and stained brown at day 4 post-surgery in the periphery of the myofibres, indicating an important decrease of ATPdependent activity in the central part of the muscles.
Thereafter, from day 8 to day 90 the extracellular matrix (ECM) and myofibre remodelling started to appear from the periphery to the central part of the myofibres, leading to increased phosphorylase activity. Finally, the regeneration of ischaemic tissue was almost complete at day 90, as mature functional muscle cells presented nuclei localisation in the periphery (left panel, straight arrows). In addition, both the regenerated myofibre composition and the high phosphorylase activity were present homogenously in the whole muscle as observed at day 90 and seem to be as in the healthy muscle before surgery.

\section{HS and CS sulphation levels are specifically} increased during ischaemia

The basal amount of total sulphated GAG was $0.75 \mu \mathrm{g}$ per mg of dried healthy muscle (Fig. 3a). As compared to this basal level, no significant difference was detected in non-ischaemic contralateral EDL over the time. After 
(a)

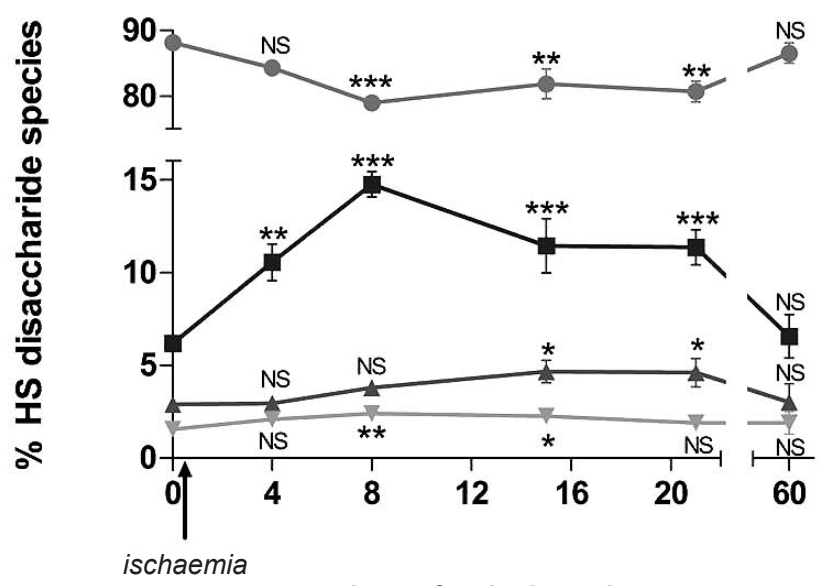

ischaemia

days after ischaemia

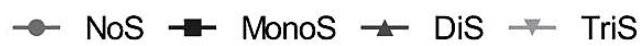

(b)

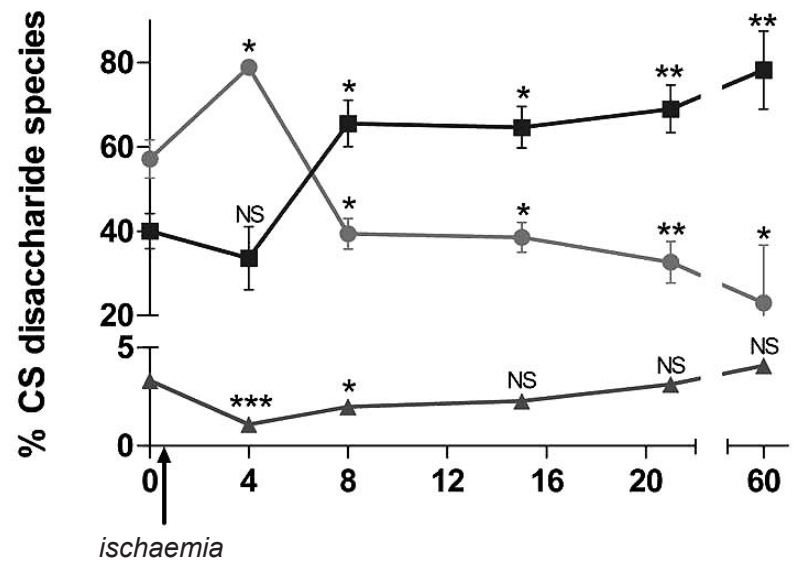

days after ischaemia

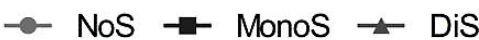

Fig. 4. Disaccharides composition of HS and CS over time following ischaemia. Disaccharides species constituting HS (a) and CS (b) extracted from $\mathrm{EDL}_{\text {normal }}$ (day 0) or $\mathrm{EDL}_{\text {isch }}(4,8,15,21$ and $60 \mathrm{~d}$ ) were determined by HPLC analysis. Values are the mean and SEM calculated from 6 individual EDL samples in 2 independent experiments for each time point (from day 0 to day $21, n=6$; day $60, n=3 ; * p<0.05,{ }^{*} * p<0.01$, $* * * p<0.001)$. surgical ligation, the GAG sulphation content increased by 3 -fold at day 4 and reached a plateau from day 8 to day 21 with a 4.5 -fold increase $(3.4 \mu \mathrm{g} / \mathrm{mg})$. Thereafter, the GAG sulphation level decreased and stabilised at $1.8 \mu \mathrm{g} / \mathrm{mg}$ at days 60 and 90, corresponding to a remaining 2.5-fold increase as compared to the initial level. The specific GAG depolymerisation by either CSase digestion or nitrous acid treatment allowed distinguishing sulphation levels among HS and CS species, respectively (Fig. 3b). Basal levels of CS or HS sulphation were 0.45 and $0.3 \mu \mathrm{g}$ per $\mathrm{mg}$ of dried healthy EDL muscle, respectively, and any significant difference was detected in contralateral EDL as for total sulphated GAG. Both HS and CS increased from day 4. HS sulphation progressively extended to a 4.3-fold increase $(1.3 \mu \mathrm{g} / \mathrm{mg})$ peak at day 15 and thereafter progressively returned to basal level at day 90. CS increased quicker and higher and reached a peak at day 8 with a 5.5 -fold increase $(2.5 \mu \mathrm{g} / \mathrm{mg})$. From day 8 , the CS sulphation level slowly decreased to $1.3 \mu \mathrm{g} / \mathrm{mg}$ by day 60 and remained stable until day 90 , demonstrating that GAG hallmark of injury observed with total GAG quantification was only composed of CS species.
Sulphation pattern of HS and CS disaccharide units evolved over the time after ischaemia

HPLC analysis allowed determining the relative composition in each disaccharide units of HS or CS species, namely the non-sulphated (NoS), the mono-sulphated (MonoS), the di-sulphated (DiS) and the tri-sulphated (TriS). HS chains from EDL $\mathrm{E}_{\text {normal }}$ were composed by $89 \%$ of NoS, $6.5 \%$ of MonoS, $3 \%$ of DiS and $1.5 \%$ of TriS disaccharide units (Fig. 4a). In EDL ${ }_{\text {isch }}$ NoS units progressively decreased to $80 \%$ from day 0 to day 21 and finally returned to the basal level at day 60 . Inversely, MonoS units increased up to $15 \%$ at day 8 , remained high until day 21, and returned to basal level at day 60. DiS units increased up to $4.7 \%$ between day 14 and 21 , whereas TriS units increased between day 8 and day 15. At day 60, all HS disaccharide units backed to the initial proportion of $\mathrm{EDL}_{\text {normal }}$. In $\mathrm{EDL}_{\text {normal }}$, $\mathrm{CS}$ chains were composed by $57 \%$ of NoS, $40 \%$ of MonoS and $3 \%$ of DiS units (Fig. 4b). In $\mathrm{EDL}_{\text {isch }}$, a peak of NoS disaccharides was observed at day 4, probably due to the amount of HA observed in Fig. 5a and which was depolymerised by CSase treatment (Yamagata $e t$ al., 1968). At day 8, NoS units greatly decreased to remain stable and 1.5-fold lower than control. Finally, from day 
(a)

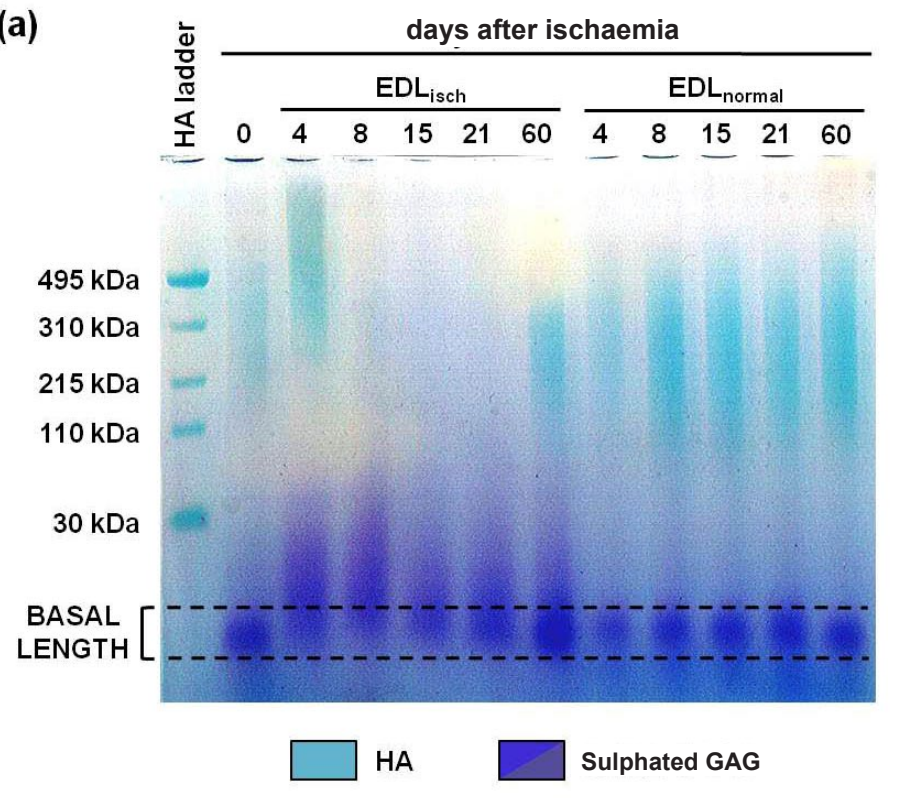

Fig. 5. GAG chain length modification over time following ischaemia. (a) Modification of the length of GAG chains was visualised by agarose gel electrophoresis and StainsAll staining. The basal length (dotted line) was determined by delimiting the upper and the lower signal of each spot of the $\mathrm{EDL}_{\text {normal }}$. Among purified GAGs, sulphated GAGs were identified by the specific dark blue/violet-staining whereas high molecular weight HA(HMW HA) was identified by the specific light blue-staining with Stains-All dye. The photography is representative of 4 independent experiments. (b) Modification of the length of CS chains was estimated by HPLC-SEC. Purified CS from 6 individual $\mathrm{EDL}_{\text {normal }}$ or $\mathrm{EDL}_{\text {isch }}$ were pooled and analysed as a single sample for each time point during 2 independent experiments $(n=2)$. GAG chain length obtained with contralateral $\mathrm{EDL}_{\text {normal }}$ served as reference.

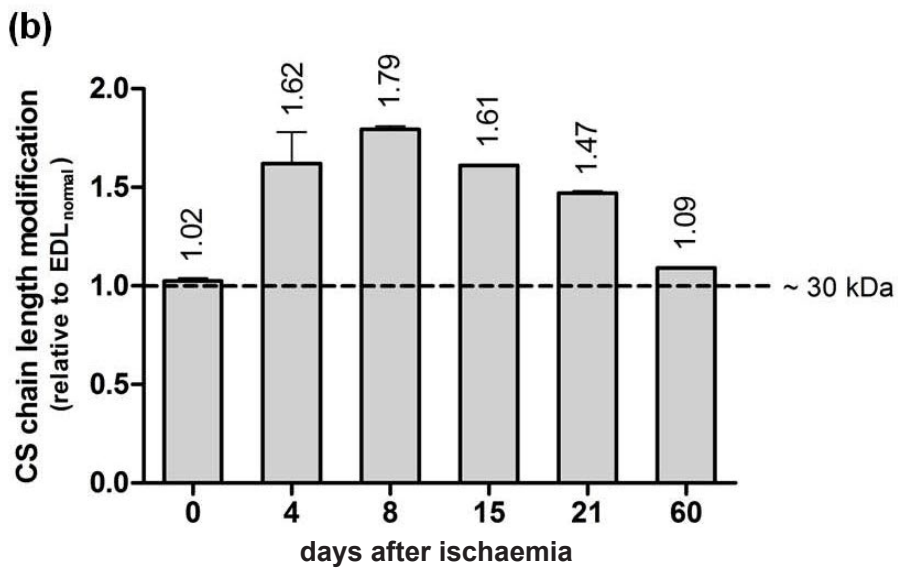

8 MonoS units are doubled, and DiS unit levels are not significantly modified. At day 60 , a significant modification of CS sulphation pattern persisted, characterised by an inversion of NoS and MonoS unit proportions.

\section{HS and CS chain lengths quickly increase after ischaemia}

Migration of purified GAGs was performed on agarose gel electrophoresis to qualitatively assess chain length modification (Fig. 5a). EDL normal $_{\text {from healthy (day 0) and }}$ contralateral muscles (days 4, 8, 15, 21 and 60) presented similar GAG chain length, thus defining a basal line. Interestingly, GAG chain length in $\mathrm{EDL}_{\text {isch }}$ increased from day 4 to day 21 as compared to this basal line and backed to the initial level at day 60. Moreover, HA presented a molecular mass between 110 and $495 \mathrm{kDa}$ in $\mathrm{EDL}_{\text {normal }}$ whereas a peak of high molecular weight HA, exceeding $495 \mathrm{kDa}$, appeared at day 4 after ischaemia and disappeared immediately after. The HA normal size reappeared at day 60 only. In order to more quantitatively compare sulphated GAG chain length modification, a size exclusion chromatographic method was performed on both $\mathrm{HS}$ and CS purified species from $\mathrm{EDL}_{\mathrm{isch}}$ and compared to contralateral EDL, used as reference with 1 as relative value. As expected, HS and CS chains length from healthy EDL (day 0) were the same as contralateral EDL. HS chain length was increased by 1.76 at day 4 after ischaemia and then immediately decreased to around 1.20 from day 8 until day 15 and finally returned to basal level after $21 \mathrm{~d}$ (data not shown). As for HS, the CS chain length increased after $4 \mathrm{~d}$ by 1.62 but continued to increase up to 1.79 -fold after 8 d (Fig. 5b). From day 15, the CS chain length started to progressively decrease and finally approached the initial length after $60 \mathrm{~d}$.

\section{GAG metabolic enzyme expression is modified following ischaemia}

HS is composed of repeating disaccharides units of glucuronic acid (GlcA) or iduronic acid (IdoA) and $\mathrm{N}$-acetyl-glucosamine (GlcNAc). Quantitative RT-PCR analysis of the expression of enzymes involved in HS biosynthesis (Fig. 6a) showed very significant increases in a majority of them as soon as day 4 with a rapid return to initial level. Both EXT1 and EXT2, enzymes involved in polymerisation of HS, were significantly up-regulated by 3.7 and 4.8-fold, respectively. HS2ST enzyme catalysing 

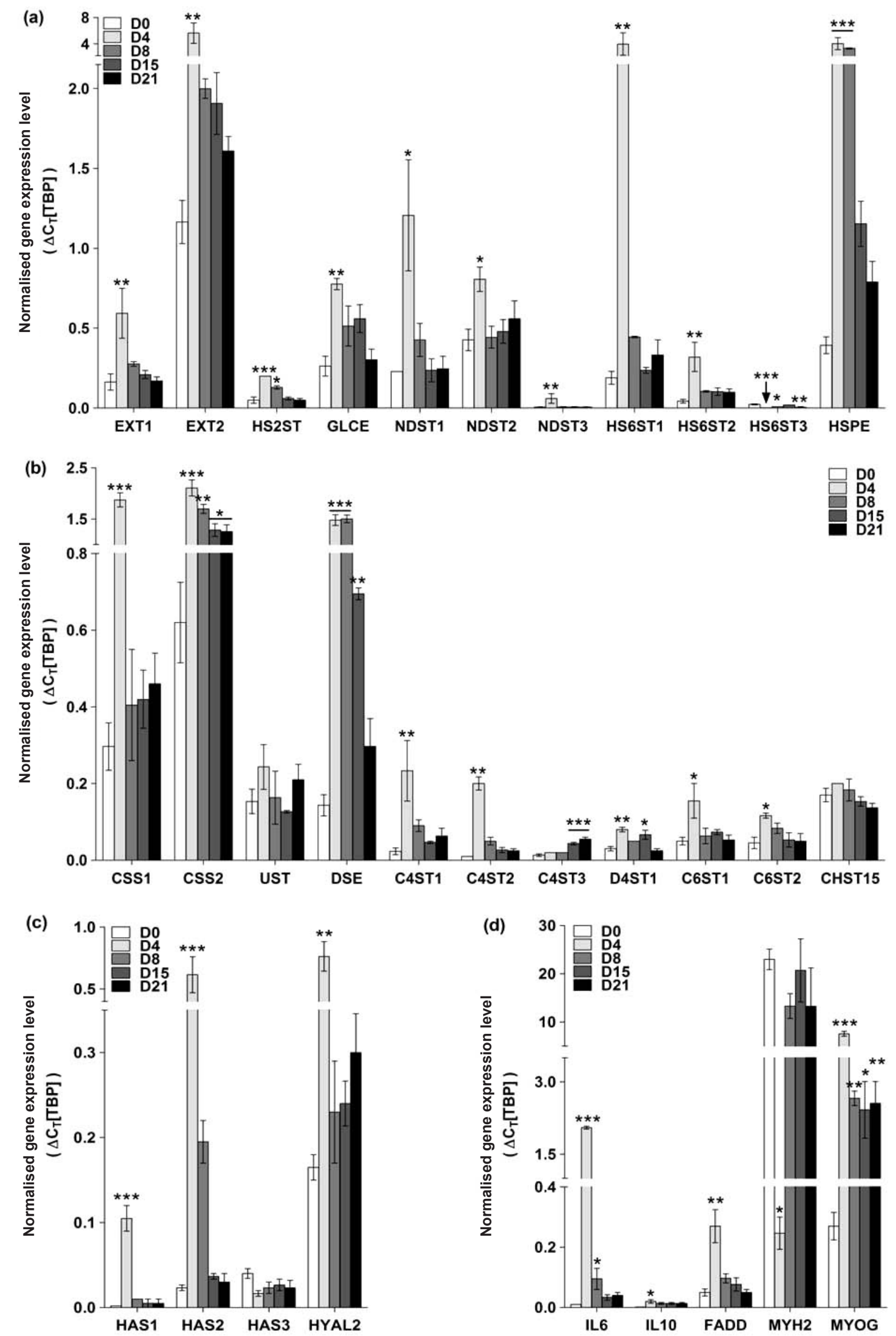

Fig. 6. GAG metabolic enzyme expression is modified following ischaemia. Gene expression of HS biosynthesis (a), CS biosynthesis (b), HA biosynthesis (c) and inflammation and muscle regeneration process (d) were determined by RTqPCR analysis. Results are presented as gene expression level following $2^{-\Delta C t}$ normalisation using TBP as housekeeping gene. Values are the mean and SEM calculated from 3 individual EDL samples $(n=3, * p<0.05$, $* * p<0.01, * * * p<0.001)$. 
Fig. 7. GAG affinities and activities toward cytokines change during the ischaemia-regeneration process. (a) GAGs from EDL $\mathrm{Ermal}_{\text {or }}$ EDL binding capacities toward FGF2 and IL8 were measured using an ELISA competition assay. Results are expressed as relative affinity after normalising to $\mathrm{EC}_{50}$ value of GAGs extracted from EDL (day 0 ). Values are the mean and SEM calculated from 3 individual EDL samples $(n=3, * p<0.05$, $* * p<0.01, * * * p<0.001$ ). (b) GAG activities in the presence of FGF2 were analysed in an in vitro model of cell proliferation using BaF32 cells. Heparin $(1 \mu \mathrm{g} / \mathrm{mL})$ was used as positive control. Values are the mean and SEM calculated from GAGs extracted from 3 individual EDL samples in 2 independent experiments $(n=6, * p<0.05$, $* * p<0.01, * * * p<0.001)$. (a)

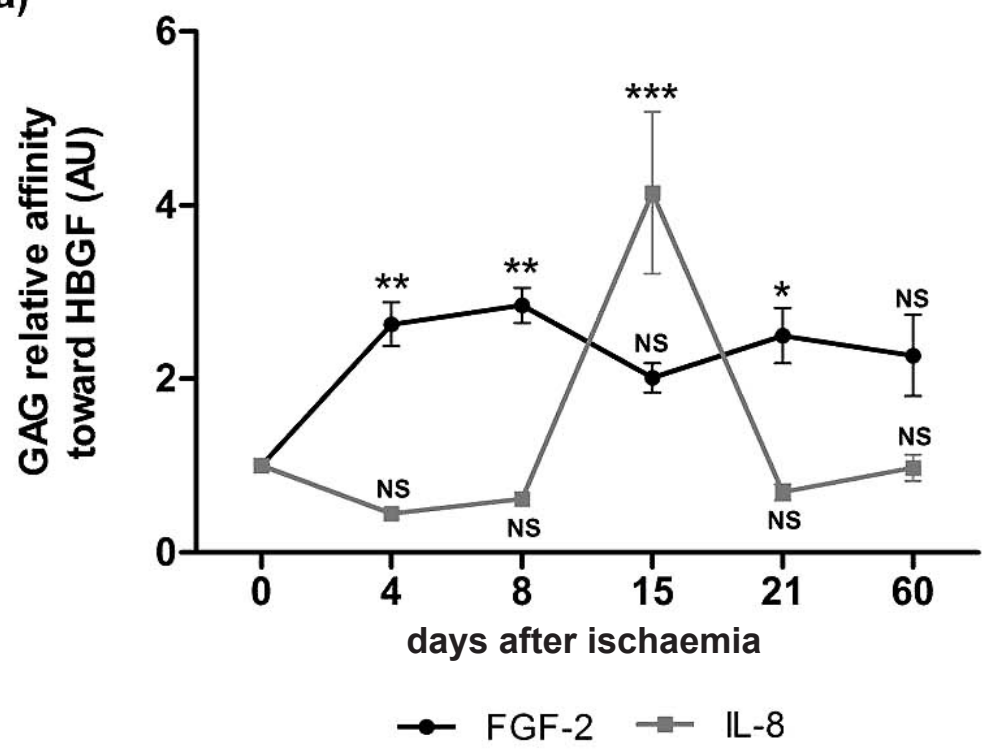

(b)

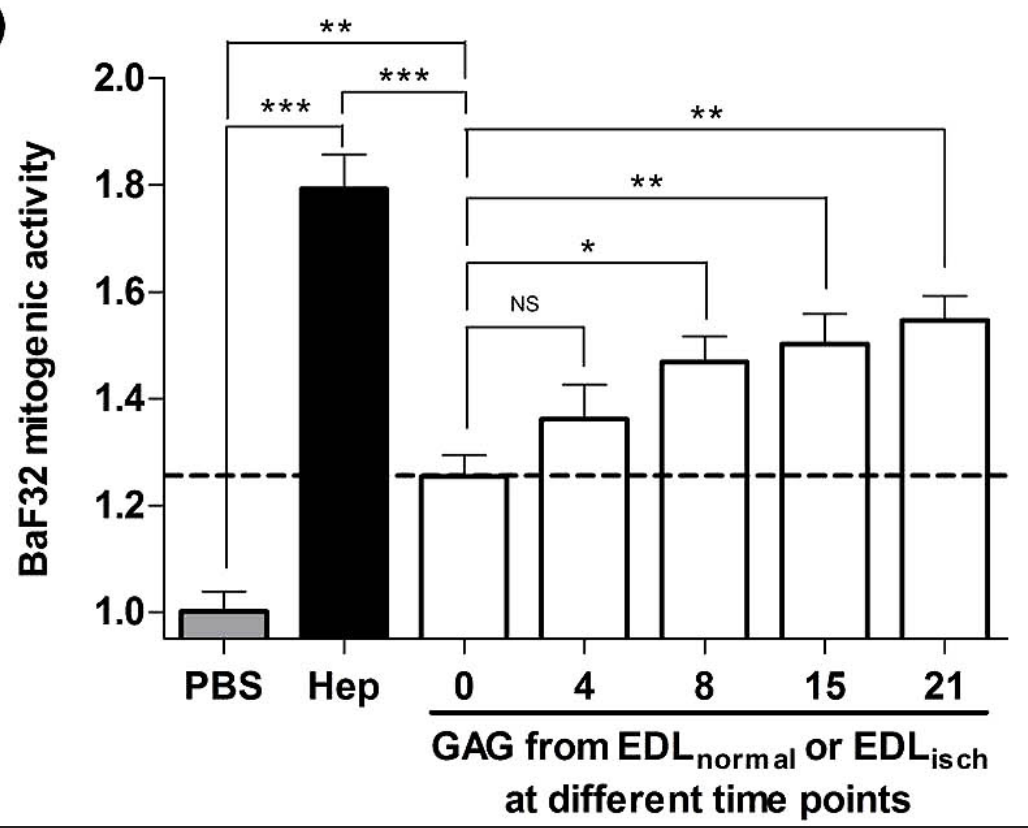

the 2-O-sulphation of GlcA/IdoA was up-regulated by 4-fold at day 4 and 2.6-fold at day 8. The expression of GLCE, an enzyme involved in epimerisation of GlcA to IdoA, was up-regulated by 3 -fold at day 4 . The expression of enzymes catalysing the $N$-sulphation (NDST family) and 6-O-sulphation (HS6ST family) of GlcNAc were also clearly modified. NDST1 and NDST2 transcripts were highly up-regulated at day 4 (5-fold and 2-fold, respectively) and NDST3 was de novo expressed as it was not detected in healthy EDL, whereas NDST4 transcripts were never detected. HS6ST-1 and -2 isoforms were highly up-regulated (20-fold and 8-fold, respectively), whereas HS6ST3 isoform was strongly down-regulated along the time course. The expression of heparanase (HSPE), responsible of the depolymerisation of HS, was up-regulated by 10 -fold from day 4 to day 8 .

CS is composed of repeating disaccharides units of GlcA or IdoA and $N$-acetyl-galactosamine (GalNAc). Analysis of enzymes involved in CS/DS biosynthesis
(Fig. 6b), showed that expression of both CS synthase CSS1 and CSS2 catalysing the polymerisation of CS were significantly up-regulated immediately after ischaemia. Whereas CSS1 expression increased by 6-fold at day 4 and returned to a basal level from day 8, higher CSS2 expression was maintained until day 21 . The expression of the UST enzyme, catalysing the $2-O$-sulphation of GlcA or IdoA, did not change over time. However, the expression of dermatan sulphate epimerase (DSE), which converts GlcA to IdoA in CS/DS biosynthesis, was strikingly increased by 10 -fold after ischaemia up to day 8 and overexpression was maintained until day 15 . Interestingly, there was a differential up-regulation of the three isoforms of C4ST enzymes catalysing 4- $O$-sulphation: C4ST1 and C4ST2 transcripts were highly up-regulated (by 10-fold and 20fold respectively) at day 4 , whereas C4ST3 transcripts were up-regulated from day 15 to day 21 . The expression of D4ST1 enzyme, allowing the 4-O-sulphation of GalNAc adjacent to IdoA, was up-regulated from day 4 to day 

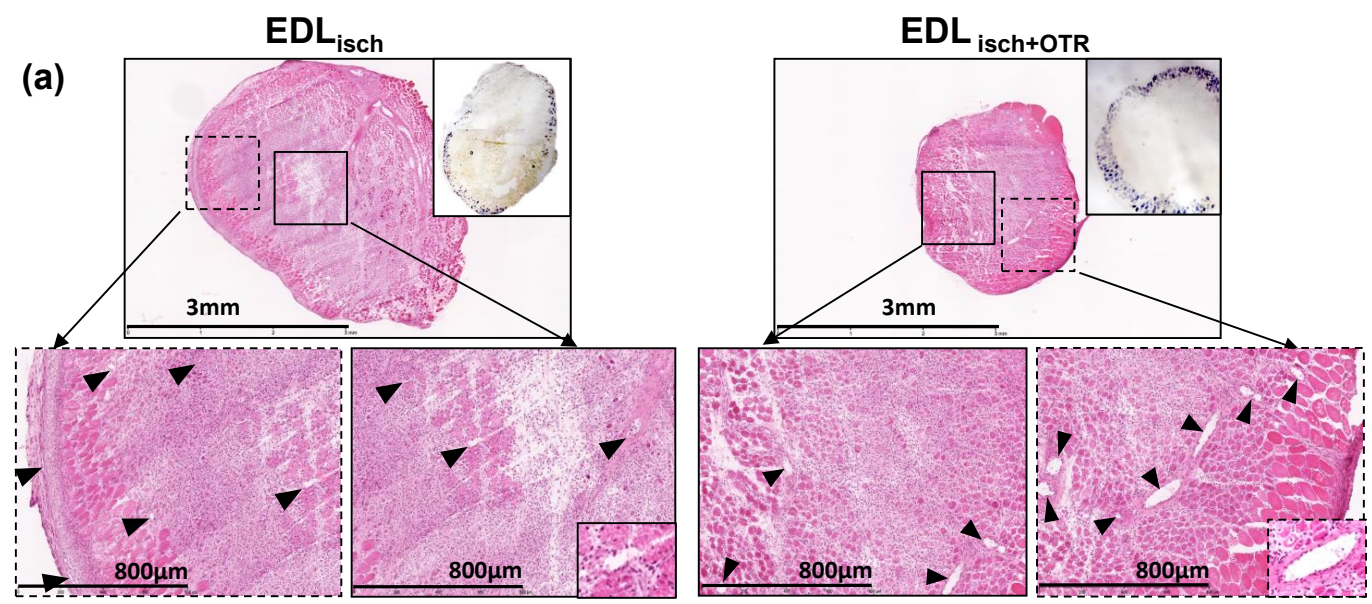

(b)
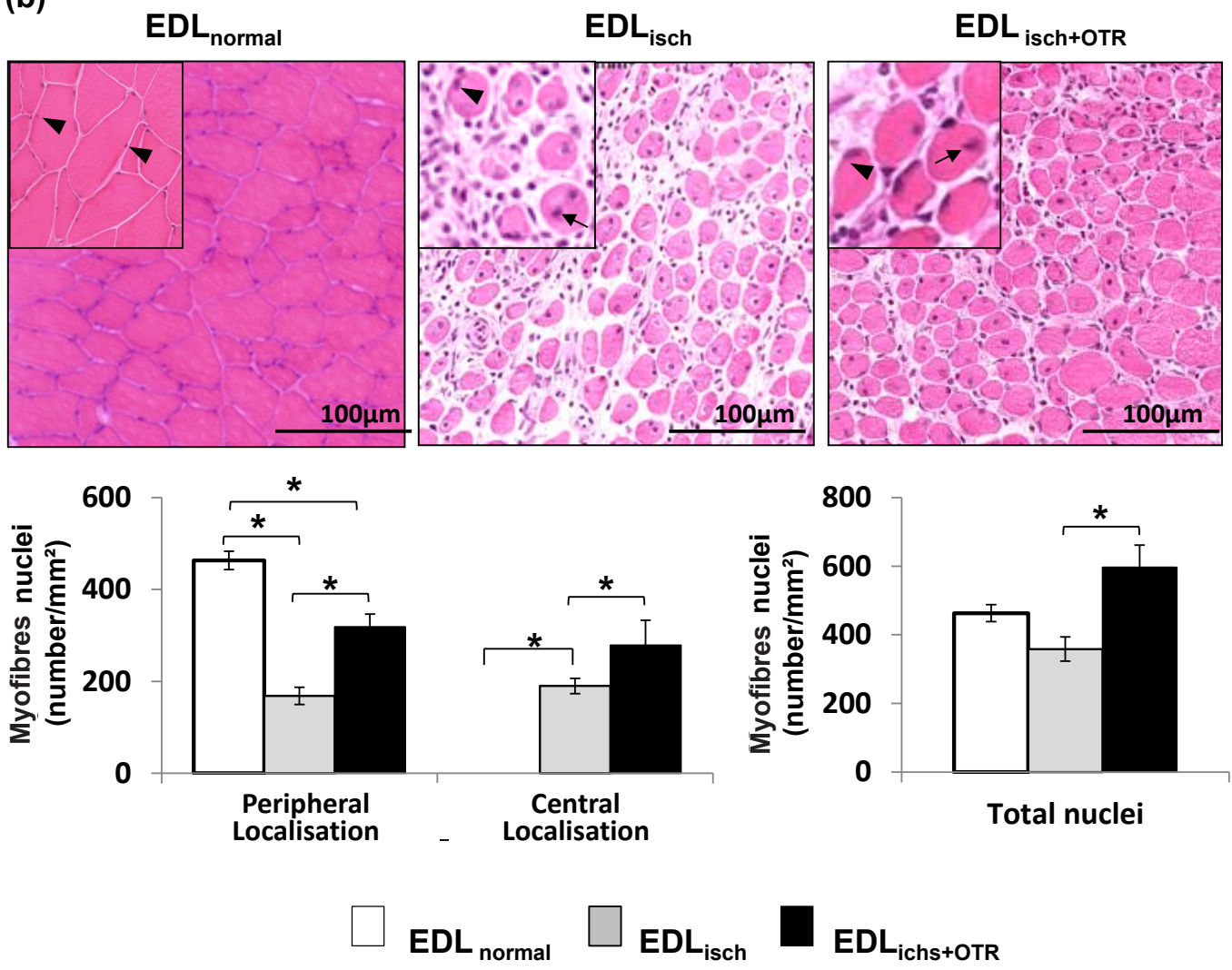

(c)
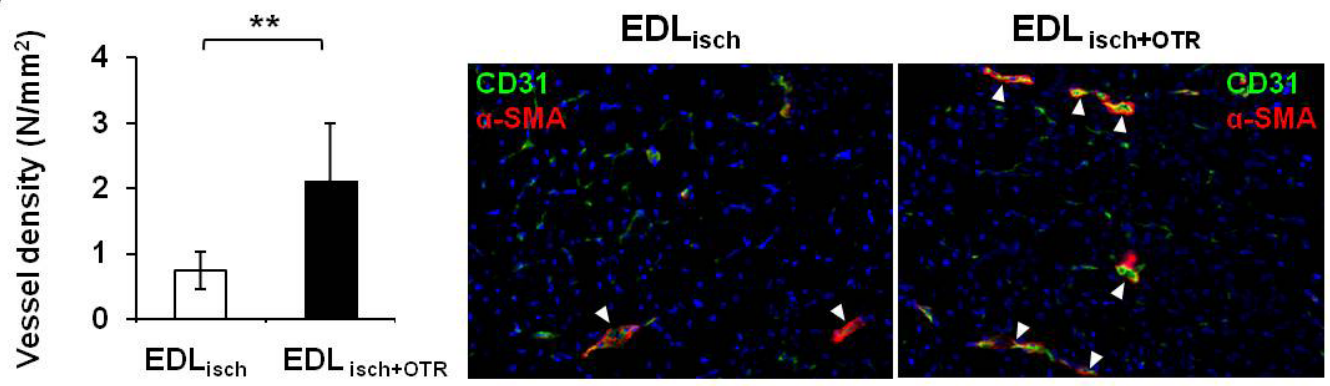

(d)

Fig. 8.

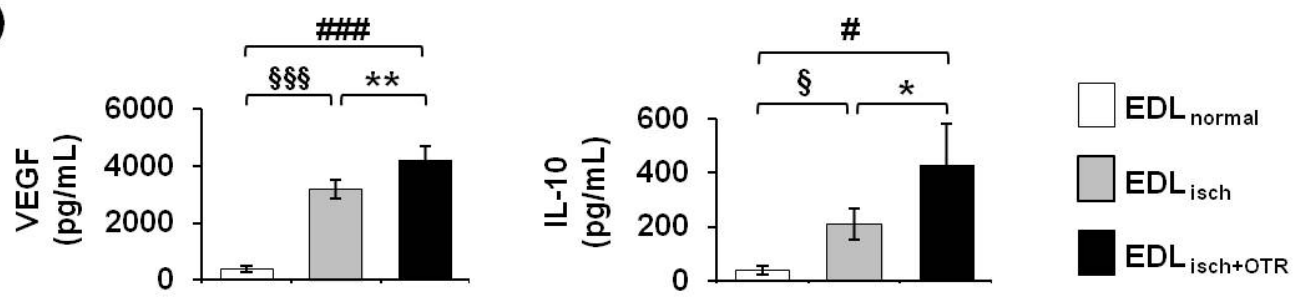


Fig. 8. (Previous page) Morphological studies of muscle sections $8 \mathrm{~d}$ after $\left[\mathrm{OTR}_{4131}\right]$ treatment. (a) Transverse sections of $\mathrm{EDL}_{\mathrm{isch}}$ and $\mathrm{EDL}_{\text {isch+OTR }}$ muscles were stained with haematoxylin-eosin and assessed for phosphorylase activity (upper panel, scale bar $=3 \mathrm{~mm}$ and lower panel with high view inserts, scale bar $=800 \mu \mathrm{m}$ ). Arrowheads indicate the presence of mature vessels. (b) Quantification of activated and mature muscle fibres with central and peripheral nuclei

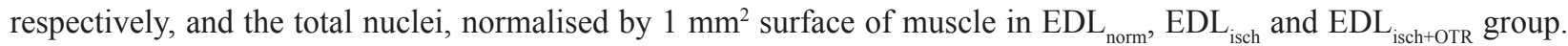
$(n=9, * * p<0.001)$, Straight arrows indicate the nuclear localisation in the peripheral part of mature cells. Arrowheads indicate the nuclear localisation in the central part of the activated cells (scale bar $=100 \mu \mathrm{m})$. (c) Quantification of total microvascular density $\left(\mathrm{N} / \mathrm{mm}^{2}\right)$ in $\mathrm{EDL}_{\text {isch }}$ or $\mathrm{EDL}_{\text {isch }+ \text { OTR }}$ groups $(n=9, * * p<0.01)$. All microvessels were identified according to double positive immunostaining for CD31 and $\alpha$-SMA (arrowheads). (d) VEGF and IL-10 levels in ischaemic tissue were measured in the supernatant of $\mathrm{EDL}_{\text {normal }}$ (non-ischaemic control), $\mathrm{EDL}_{\text {isch }}$ (placebo-treated), and

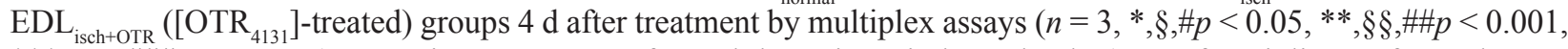
$* * *, \S \S \S, \# \# \# p<0.0001)$. Experiments were performed three times independently $(n=9$ for triplicate of samples per groups in 3 independent experiments).

15. Slight modifications were observed for enzymes catalysing the 6-O-sulphation of GalNAc, as C6ST1 and C6ST2 expression were transiently up-regulated at day 4. The expression of the CHST15 enzyme, transferring a sulphate group on GalNAc-4S, did not change. Finally, the expression of the CS hydrolase CSHY enzyme, involved in the degradation of CS, was not detected in all samples.

Concerning enzymes involved in the biosynthesis of HA (Fig. 6c), two isoforms of HA synthase, HAS1 and HAS2 involved in high molecular weight HA synthesis (Itano et al., 1999), were strongly up-regulated by 50-fold and 30 -fold respectively at day 4 , whereas no modification of the HAS3 isoform, implicated in the synthesis of low molecular weight HA (Itano et al., 1999), was observed. The HA-degrading enzyme HYAL2 was also up-regulated at the same time and suggests a rapid degradation of HA to oligosaccharides.

All of these data clearly indicate that muscle ischaemia rapidly induces a major modification of GAG structure through the regulation of enzymes involved in their biosynthesis and degradation. Finally, gene expression involved in muscle injury and regeneration was also analysed (Fig. 6d). Over-expression by 200-fold of IL6, related to a pro-inflammatory process, occurred a few days after ischaemia and persisted up to day 8. The IL10 transcripts related to an anti-inflammatory process, were not detected in $\mathrm{EDL}_{\text {normal }}$, and de novo expressed in $\mathrm{EDL}_{\text {iscl }}$ along the time course. Muscle damage was confirmed by cell death related to the elevated expression of fas associated via death domain (FADD) transcripts and the lost expression of myosin heavy chain 2 (MYH2) marker of mature muscle at day 4 , whereas induced muscle regeneration along the time course was associated with the up-regulation of myogenin transcripts.

\section{GAGs from injured EDL display differential binding affinities toward growth factors}

The capacity of GAGs to regulate protein functions is largely related to their abilities to bind to HBPs. An ELISAbased competitive binding assay was used to investigate if structural modifications of GAGs after ischaemia are associated to distinct abilities to bind HBPs. GAGs from EDL $_{\text {normal }}$ were able to bind to FGF2 and IL8 and to inhibit their binding to heparin with $\mathrm{EC}_{50}$ values of 2.7 and $15 \mu \mathrm{g} /$ $\mathrm{mL}$, respectively (data not shown). These were taken as relative values (1) to compare binding capacities of extracted GAGs. As shown in Fig. 7a, GAGs from EDL isch $_{\text {, }}$ have significant higher capacities, around 2.5-fold, to bind to FGF2 throughout the time course. In contrast, IL8 binding capacity significantly increased by 4 -fold only after $15 \mathrm{~d}$ following ischaemia. Thus, the capacities of GAGs to bind HBPs were significantly modified in $\mathrm{EDL}_{\text {isch }}$ depending on each individual growth factor.

\section{GAGs from injured EDL potentiate FGF2 mitogenic activity}

To investigate if GAGs extracted after ischaemia could have modified abilities to potentiate HBPs activities we used a mitogenic activity assay on BaF32 cells, a cell line devoid of cell surface HS and transfected with the FGF receptor type 1. These cells respond to FGF2 only in the presence of exogenous GAGs or heparin (Ornitz et al., 1992). Effectively, heparin potentiated FGF2induced proliferation on BaF32 cells by 1.8 -fold as compared to PBS (Fig. 7b). The same dose of extracted GAGs from $\mathrm{EDL}_{\text {normal }}$ potentiated it only by 1.3 -fold. Interestingly, the potentiating effect of extracted GAGs from $\mathrm{EDL}_{\text {isch }}$ throughout the time course of ischaemia was increased. GAGs extracted from $\mathrm{EDL}_{\text {isch }}$ at day 8 to day 21 significantly potentiated the proliferation by 1.5 -fold.

\section{[OTR ${ }_{4131}$ ] treatment improves muscle regeneration}

The therapeutic effect of GAG mimetic treatment was investigated by intra-muscular injection of $\left[\mathrm{OTR}_{4131}\right]$ compound just after the surgical procedure. Since it has been previously described that the most important effect of the GAG mimetic treatment is observed after $8 \mathrm{~d}$ compared to saline-placebo treatment (Desgranges et al., 1999), we performed histological staining at this time point. As observed in Fig. 8a, the ischaemic process was inhibited and muscle regeneration was started from the periphery of myofibres in the EDL isch + OTR $_{\text {group, as compared to control }}$ placebo-treated $\mathrm{EDL}_{\text {isch }}$ group. In addition, the $\left[\mathrm{OTR}_{4131}\right]$ beneficial action on the ischaemic myofibres was analysed by phosphorylase assay. The increased phosphorylase activity in the $\mathrm{EDL}_{\text {isch }+ \text { OTR }}$ group evidenced the presence of mature and functional myofibres not observed in the EDL $_{\text {isch }}$ group (Fig. 8a, insert). The myofibre maturation was confirmed by the analysis of nuclei localisation in the myofibres (Fig. 8b). A quantification of activated and mature muscle fibres with central and peripheral nuclei, respectively, as well as the total nuclei, was performed and 
normalised by surface of muscle of $1 \mathrm{~mm}^{2}$ for three groups of animal: $\mathrm{EDL}_{\text {normal }}, \mathrm{EDL}_{\text {isch }}$ and $\mathrm{EDL}_{\text {isch }+ \text { OTR }}$ (Fig. 8b). A significant $64 \pm 3 \%$ decrease $(* p<0.05)$ of peripheral nuclei was observed in $\mathrm{EDL}_{\text {normal }}(463 \pm 18)$ as compared to $\mathrm{EDL}_{\text {isch }}(168 \pm 18)$, and centrally located nuclei appeared ( 0 in $\mathrm{EDL}_{\text {normal }}$ vs. $190 \pm 17$ in $\mathrm{EDL}_{\text {isch }}$ ) $8 \mathrm{~d}$ following ischaemia, consistent with a spontaneous regenerating process in damaged muscles. The $\left[\mathrm{OTR}_{4131}\right]$ treatment induced a $69 \pm 3 \%$ recovery of peripheral located nuclei as compared to healthy EDL (463 \pm 18 in $\mathrm{EDL}_{\text {normal }} v s$. $318 \pm 28$ in $\mathrm{EDL}_{\text {isch }+\mathrm{OTR}}$ ) together with a $31 \pm 7 \%$ increase of central nuclei as compared to ischaemic untreated $\operatorname{EDL}\left(190 \pm 17\right.$ in $\mathrm{EDL}_{\text {isch }}$ vs. $278 \pm 54$ in $\left.\mathrm{EDL}_{\text {isch }+\mathrm{OTR}}\right)$. These significant results indicated both an acceleration of muscle fibre maturation and a stimulation of muscle regeneration $(* p<0.05)$. In addition, total number of nuclei was increased significantly up to $66 \pm 13 \%$ in ischaemic EDL after $\left[\mathrm{OTR}_{4131}\right]$ treatment $\left(358 \pm 35\right.$ in $\mathrm{EDL}_{\text {isch }} v s$. $596 \pm 65$ in $\left.\mathrm{EDL}_{\text {isch }+ \text { OTR }}, * p<0.05\right)$. Moreover, the total number of nuclei in treated EDL is higher by $28 \pm 9 \%$

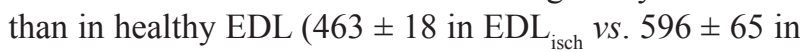
$\left.\mathrm{EDL}_{\text {isch }+ \text { OTR }} * p<0.05\right)$, indicating that $\left[\mathrm{OTR}_{4131}\right]$ treatment not only improves the maturation but also the number of regenerating myofibres.

Since muscle regeneration after ischaemia is related to neoangiogenesis, we evaluated the effect of the $\left[\mathrm{OTR}_{4131}\right]$ treatment on vessel formation at day 8 of treatment (Fig. $8 \mathrm{c}$ ). Quantification of the microvessels was performed in the total surface of muscle cross-section, according to immunostaining of endothelial cells (CD31+) and smooth muscle cells $(\alpha-\mathrm{SMA}+)$. The corresponding microvessel density $\left(\mathrm{N} / \mathrm{mm}^{2}\right)$ was significantly increased in the $\mathrm{EDL}_{\text {isch }+ \text { OTR }}$ group $\left(2.1 \pm 0.9 / \mathrm{mm}^{2}\right)$ as compared to the $\mathrm{EDL}_{\text {isch }}$ group $\left(0.74 \pm 0.3 / \mathrm{mm}^{2}\right)$. In addition, VEGF and IL-10 secreted levels were significantly increased in the $\left[\mathrm{OTR}_{4131}\right]$-treated muscle (Fig. 8d). All these results suggested that $\left[\mathrm{OTR}_{4131}\right]$ GAG mimetic potentiates angiogenesis in damaged muscles.

\section{Discussion}

The presence of ECM compounds is essential for normal myogenesis in vitro (Melo et al., 1996; Osses and Brandan, 2002), offering to the cell not only an optimal mechanical environment to survive but also the necessary signals to grow, differentiate, move, and respond to stress. A recent proteomic study reveals a biosignature of early- and late-stage ECM remodelling after myocardial ischaemia-reperfusion injury (Barallobre-Barreiro et al., 2012). Thus, the quality of the ECM can influence the function of chemical signals and effectors in tissue repair (Marastoni et al., 2008). Herein we present a glycomic study and described for the first time GAG remodelling after ischaemia in the rat EDL.

\section{HS and CS species structurally evolve in distinct ways after ischaemia}

We demonstrate that the sulphation level of GAGs strongly increases immediately after ischaemia and progressively decreases up to $60 \mathrm{~d}$, as previously described after induced- ischaemia in the heart (Drobnik et al., 2004). These changes in sulphation level of both HS and CS are explained in part by the enriched proportion of sulphated disaccharides all along the GAG chains and an increase in chain length. However, these data do not exclude the possibility of an increased number of GAG chains. Moreover, all of these results are consistent with an up-regulation of the expression of the enzymes involved in HS and CS modifications, correlated with the different waves of HS and CS sulphation levels. Interestingly, while the enzymes involved in HS chain modification are up-regulated soon at day 4 after ischaemia, then return quickly to basal level, expression levels of heparanase are modulated in the same way. This suggests that HS changes during the ischaemiarepair process involve de novo synthesis and sulphation as well as a degradation step. In contrast, the enzymes involved in CS modification are mainly up-regulated at day 4 too but remain elevated for some isoforms up to day 21, whereas absence of active CS degradation was suggested by undetected chondroitin sulphate hydrolase expression. Such a pattern could explain the presence of a "CS scare" observed from $60 \mathrm{~d}$ following ischaemia as a glycomic hallmark of injury. In another context of the muscle degeneration-regeneration process, we recently have shown that such an elevated level of CS is also found in the advanced stage of human dystrophic muscles (Negroni et al., 2014). The functional role of this CS scare remains to be explored.

\section{Fine structure of GAGs is a crucial determinant to modulate muscle repair}

Our results indicate an increased sulphation of HS species that could be associated to the modulation of growth factor activities driving muscle repair after ischaemia. This modified pattern is characterised by a strong upregulation of sulfotransferases, relevant with the role of HS sulphation in myogenesis and muscle regeneration. HS 6-O-sulphation through HS6ST enzymes is essential for muscle development (Bink et al., 2003) and is required for the binding of growth factors such as FGF2, HGF and VEGF which are implicated in muscle regeneration (Narita et al., 2006). Moreover, HS 6-O-sulphation is essential for FGF2 signalling inducing satellite cell proliferation and inhibiting myoblast fusion during the early phase of muscle regeneration (Langsdorf et al., 2007; Tran et al., 2012). HS also plays a role during the inflammatory step of muscle repair, since HS sulphation through NDST enzymes increases the chemotactic gradient of RANTES/CCL5 and IL8, both involved in the recruitment of leukocytes (Carter et al., 2003; Wang et al., 2005). Concerning angiogenesis, overexpression of NDST enzymes induced by hypoxia results in high sensibility of endothelial cells to FGF2 associated with increased proliferation (Li et al., 2002). More surprisingly, we demonstrate for the first time that sulphated GAG modification during muscle regeneration is mainly related to neosynthesis of CS chains composed of more monosulphated disaccharides and longer chain length and is stabilised as a glycomic hallmark of ischaemiainduced injury. If the role of HS has been extensively studied in many biological processes, including muscle repair, little is known about the role of CS. Even if PGs 
carrying CS chains have been demonstrated as regulators of TGF- $\beta$ signalling (Droguett et al., 2006), their roles remain elusive. Some in vitro studies have pointed out the role of CS/DS chains in the control of muscle regeneration: DS chains potentiate the FGF2- or HGF-induced proliferation and migration of myoblasts (Villena and Brandan, 2004), whereas CS chains of myoblasts are dramatically diminished at the stage of extensive syncytial myotube formation (Mikami et al., 2012). Our results are consistent with the recent demonstration that in vivo injection of a CS-degrading enzyme boosts myofibre regeneration and ameliorates dystrophic pathology in $m d x$ muscles (Mikami et al., 2012). Besides modification of sulphated GAGs, we demonstrated that HA biosynthesis is modulated in vivo during ischaemic process development in rat EDL. As it was already demonstrated that oligosaccharides of HA promote both the production of pro-inflammatory cytokines and angiogenesis (Stern et al., 2006), we suggest that such transient increase of HA could be involved in the initiation of inflammatory and angiogenic processes, essential for muscle repair. Finally, all of these data suggest that the control of GAG composition in ECM could be a promising new therapeutic approach for the treatment of skeletal muscle injury.

\section{GAG affinities toward HBPs change to modulate cell function following ischaemia}

In this study, we demonstrate that ischaemia and the repair process are associated to an enrichment of GAG chains with sulphate groups and probably iduronic acid, which are structural features implicated in more flexible chains with increased binding potentials for ligands (Gandhi and Mancera, 2008; Thelin et al., 2013). The relevance of such structural modifications after ischaemia was validated since we demonstrated that the sulphated GAGs affinities evolve differently over time toward FGF2 and IL8, both HBPs released from the damaged myofibres (Akerstrom et al., 2005; Clarke et al., 1993). FGF2 has been implicated in satellite cell migration and proliferation (Yablonka-Reuveni et al., 1999) and inhibition of myofibre differentiation (Allen and Boxhorn, 1989). IL8 mediates neutrophil recruitment, accumulation, and their function at sites of inflammation (Knall et al., 1997). Furthermore, both FGF2 and IL8 are regulators of angiogenesis (Chen et al., 2004; Koch et al., 1992). Moreover, GAGs displaying elevated binding affinities toward FGF2 potentiate FGF2induced proliferation in vitro. All of these data suggest that a defined control of GAG structure takes place after ischaemia in order to modulate specific regeneration steps through modulation of HBP activity.

\section{$\left[\mathrm{OTR}_{4131}\right]$ accelerates neovascularisation and ischaemic muscle regeneration}

Rat EDL ischaemia was associated with rapid inflammatory cell infiltration and myofibre degradation $4 \mathrm{~d}$ after ischaemia, with a spontaneous regeneration after $15 \mathrm{~d}$. We demonstrated here that ischaemia is associated with strong GAG remodelling with modification of HBP activities, and we validated that $\left[\mathrm{OTR}_{4131}\right]$ GAG mimetic treatment accelerates myofibre reconstruction and vessel formation earlier from day 8 of post-surgery. This regenerative effect is probably related to the resistance of GAG mimetics to enzymatic degradation (Meddahi et al., 2002; Meddahi et al., 1995), thus leading to better HBP protection in an ischaemic environment. Indeed, as already described for others synthetic GAGs, the $\left[\mathrm{OTR}_{4131}\right]$-binding to VEGF may protect it from inhibition and proteolytic cleavage thus increasing its bioavailability and potentiating its affinity for specific receptor, leading to better angiogenesis (Rouet et al., 2005; Rouet et al., 2006). The protection of IL10 as well could accelerate muscle regeneration, as it was demonstrated that this interleukin promotes muscle growth and regeneration following injury (Deng et al., 2012). In addition, $\left[\mathrm{OTR}_{4131}\right]$ may participate in the restoration of normal ECM as it was already described that another GAG mimetic induces a recovery of normal collagen I and III levels and organisation, with no evidence of fibrosis (Barbier-Chassefiere et al., 2009). Accordingly, we previously reported that the treatment with others GAGs mimetics improves pig myocardium function recovery after ischaemia (Yamauchi et al., 2000) and both protects muscle fibres from degeneration and preserves the differentiated state of the surviving fibres in ischaemic and denervated rat EDL (Desgranges et al., 1999). In the same way, we also previously demonstrated that fucoidan, a natural polysaccharide extracted from marine brown algae, induces revascularisation in a rat model of critical hindlimb ischaemia (Luyt et al., 2003). Moreover, we previously demonstrated that $\left[\mathrm{OTR}_{4131}\right]$ mobilises haematopoietic stem cells according to SDF1 gradient (Albanese et al., 2009) and potentiates VEGF effects on endothelial progenitor cell (EPC) properties (Chevalier et al., 2014). Thus, further studies are needed to determine if $\left[\mathrm{OTR}_{4131}\right]$ treatment could have increased angiogenesis through potentiating the homing of EPC from the bone marrow niche to the neo-angiogenesis site of injury by the dual VEGF-SDF-1 gradient (Rabbany et al., 2003; Yamaguchi et al., 2003). All together these data highlight the importance of the glycanic component of the ECM in tissue homeostasis and suggest that sulphated polysaccharides, such as GAG mimetics, represent potential therapeutic agents for promoting angiogenesis and tissue repair.

\section{Conclusion}

We demonstrate that an intense time-dependant GAG species remodelling occurs following muscle ischaemia and suggests specific roles for HS, CS and HA on muscle regeneration. Fine modifications of the structure of GAGs along the time of regeneration after ischaemia, such as hyper-sulphation and chains length were characterised and involved in modulation of growth factor activities. In this context, we validated the interest to use GAG mimetics such as $\left[\mathrm{OTR}_{4131}\right]$ to restore a proper microenvironment that potentiates neovascularisation and accelerates ischaemic muscle regeneration. This opens a new path of investigation on the role of endogenous GAGs in modulation of muscle repair. 


\section{Acknowledgments}

This work was supported by Region Ile-de-France doctoral fellowship for F. Chevalier (STEMP-RVTUNIVPARISEST-AD-P10). We also acknowledge the financial support from the French National Research Agency (ANR-010-TecSan-2010). We wish to confirm that there are no known conflicts of interest associated with this publication and there has been no significant financial support for this work that could have influenced its outcome.

\section{References}

Akerstrom T, Steensberg A, Keller P, Keller C, Penkowa M, Pedersen BK (2005) Exercise induces interleukin-8 expression in human skeletal muscle. J Physiol 563: 507 516.

Albanese P, Caruelle D, Frescaline G, Delbe J, PetitCocault L, Huet E, Charnaux N, Uzan G, Papy-Garcia D, Courty J (2009) Glycosaminoglycan mimetics-induced mobilization of haematopoietic progenitors and stem cells into mouse peripheral blood: structure/function insights. Exp Hematol 37: 1072-1083.

Allen RE, Boxhorn LK (1989) Regulation of skeletal muscle satellite cell proliferation and differentiation by transforming growth factor-beta, insulin-like growth factor I, and fibroblast growth factor. J Cell Physiol 138: 311-315.

Barallobre-Barreiro J, Didangelos A, Schoendube FA, Drozdov I, Yin X, Fernandez-Caggiano M, Willeit P, Puntmann VO, Aldama-Lopez G, Shah AM, Domenech N, Mayr M (2012) Proteomics analysis of cardiac extracellular matrix remodeling in a porcine model of ischaemia/ reperfusion injury. Circulation 125: 789-802.

Barbier-Chassefiere V, Garcia-Filipe S, Yue XL, Kerros ME, Petit E, Kern P, Saffar JL, Papy-Garcia D, Caruelle JP, Barritault D (2009) Matrix therapy in regenerative medicine, a new approach to chronic wound healing. J Biomed Mater Res A 90: 641-647.

Barbosa I, Garcia S, Barbier-Chassefiere V, Caruelle JP, Martelly I, Papy-Garcia D (2003) Improved and simple micro assay for sulphated glycosaminoglycans quantification in biological extracts and its use in skin and muscle tissue studies. Glycobiology 13: 647-653.

Berger JS, Hiatt WR (2012) Medical therapy in peripheral artery disease. Circulation 126: 491-500.

Bink RJ, Habuchi H, Lele Z, Dolk E, Joore J. Rauch, GJ, Geisler R, Wilson SW, den Hertog J, Kimata K, Zivkovic D (2003) Heparan sulphate 6-O-sulfotransferase is essential for muscle development in zebrafish. $\mathrm{J}$ Biol Chem 278: 31118-31127.

Campbell JJ, Hedrick J, Zlotnik A, Siani MA, Thompson DA, Butcher EC (1998) Chemokines and the arrest of lymphocytes rolling under flow conditions. Science 279: 381-384.

Carlson BM, Gutmann E (1975) Regneration in free grafts of normal and denervated muscles in the rat: morphology and histochemistry. Anat Rec 183: 47-62.

Carter NM, Ali S, Kirby JA (2003) Endothelial inflammation: the role of differential expression of
$\mathrm{N}$-deacetylase/N-sulphotransferase enzymes in alteration of the immunological properties of heparan sulphate. J Cell Sci 116: 3591-3600.

Casar JC, Cabello-Verrugio C, Olguin H, Aldunate R, Inestrosa NC, Brandan E (2004) Heparan sulphate proteoglycans are increased during skeletal muscle regeneration: requirement of syndecan-3 for successful fiber formation. J Cell Sci 117: 73-84.

Chen CH, Poucher SM, Lu J, Henry PD (2004) Fibroblast growth factor 2: from laboratory evidence to clinical application. Curr Vasc Pharmacol 2: 33-43.

Chevalier F, Lavergne M, Negroni E, Ferratge S, Carpentier G, Gilbert-Sirieix M, Sineriz F, Uzan G, Albanese P (2014) Glycosaminoglycan mimetic improves enrichment and cell functions of human endothelial progenitor cell colonies. Stem Cell Res 12: 703-715.

Clarke MS, Khakee R, McNeil PL (1993) Loss of cytoplasmic basic fibroblast growth factor from physiologically wounded myofibres of normal and dystrophic muscle. J Cell Sci 106: 121-133.

Cornelison DD, Filla MS, Stanley HM, Rapraeger AC, Olwin BB (2001) Syndecan-3 and syndecan-4 specifically mark skeletal muscle satellite cells and are implicated in satellite cell maintenance and muscle regeneration. Dev Biol 239: 79-94.

Crisco JJ, Jokl P, Heinen GT, Connell MD, Panjabi MM (1994) A muscle contusion injury model. Biomechanics, physiology, and histology. Am J Sports Med 22: 702-710.

Deng B, Wehling-Henricks M, Villalta SA, Wang Y, Tidball JG (2012) IL-10 triggers changes in macrophage phenotype that promote muscle growth and regeneration. J Immunol 189: 3669-3680.

Desgranges P, Barbaud C, Caruelle JP, Barritault D, Gautron J (1999) A substituted dextran enhances muscle fiber survival and regeneration in ischaemic and denervated rat EDL muscle. FASEB J 13: 761-766.

Desouza CV, Hamel FG, Bidasee K, O’Connell K (2011) Role of inflammation and insulin resistance in endothelial progenitor cell dysfunction. Diabetes 60: 12861294.

Drobnik J, Szczepanowska A, Dabrowski R (2004) Temporary augmentation of glycosaminoglycans content in the heart after left coronary artery ligation. Pathophysiology 11: 35-39.

Droguett R, Cabello-Verrugio C, Riquelme C, Brandan E (2006) Extracellular proteoglycans modify TGF-beta bio-availability attenuating its signaling during skeletal muscle differentiation. Matrix Biol 25: 332-341.

Friedl A, Chang Z, Tierney A, Rapraeger AC (1997) Differential binding of fibroblast growth factor-2 and -7 to basement membrane heparan sulphate: comparison of normal and abnormal human tissues. Am J Pathol 150: 1443-1455.

Gandhi NS, Mancera RL (2008) The structure of glycosaminoglycans and their interactions with proteins. Chem Biol Drug Des 72: 455-482.

Garcia-Filipe S, Barbier-Chassefiere V, Alexakis C, Huet E, Ledoux D, Kerros ME, Petit E, Barritault D, Caruelle JP, Kern P (2007) RGTA OTR4120, a heparan sulphate mimetic, is a possible long-term active agent to heal burned skin. J Biomed Mater Res A 80: 75-84. 
Goussetis E, Manginas A, Koutelou M, Peristeri I, Theodosaki M, Kollaros N, Leontiadis E, Theodorakos A, Paterakis G, Karatasakis G, Cokkinos DV, Graphakos $S$ (2006) Intracoronary infusion of CD133+ and CD133CD34+ selected autologous bone marrow progenitor cells in patients with chronic ischaemic cardiomyopathy: cell isolation, adherence to the infarcted area, and body distribution. Stem Cells 24: 2279-2283.

Handel TM, Johnson Z, Crown SE, Lau EK, Proudfoot AE (2005) Regulation of protein function by glycosaminoglycans - as exemplified by chemokines. Annu Rev Biochem 74: 385-410.

Huynh MB, Morin C, Carpentier G, Garcia-Filipe S, Talhas-Perret S, Barbier-Chassefiere V, van Kuppevelt TH, Martelly I, Albanese P, Papy-Garcia D (2012a) Age-related changes in rat myocardium involve altered capacities of glycosaminoglycans to potentiate growth factor functions and heparan sulphate-altered sulphation. J Biol Chem 287: 11363-11373.

Huynh MB, Villares J, Diaz JE, Christiaans S, Carpentier G, Ouidja MO, Sissoeff L, Raisman-Vozari R, Papy-Garcia D (2012b) Glycosaminoglycans from aged human hippocampus have altered capacities to regulate trophic factors activities but not Abeta42 peptide toxicity. Neurobiol Aging 33: 1005 e11-22.

Itano N, Sawai T, Yoshida M, Lenas P, Yamada Y, Imagawa M, Shinomura T, Hamaguchi M, Yoshida Y, Ohnuki Y, Miyauchi S, Spicer AP, McDonald JA, Kimata $\mathrm{K}$ (1999) Three isoforms of mammalian hyaluronan synthases have distinct enzymatic properties. J Biol Chem 274: 25085-25092.

Knall C, Worthen GS, Johnson GL (1997) Interleukin 8-stimulated phosphatidylinositol-3-kinase activity regulates the migration of human neutrophils independent of extracellular signal-regulated kinase and p38 mitogenactivated protein kinases. Proc Natl Acad Sci USA 94: 3052-3057.

Koch AE, Polverini PJ, Kunkel SL, Harlow LA, DiPietro LA, Elner VM, Elner SG, Strieter RM (1992) Interleukin-8 as a macrophage-derived mediator of angiogenesis. Science 258: 1798-1801.

Kochtebane N, Passefort S, Choqueux C, Ainoun F, Achour L, Michel JB, Back M, Jacob MP (2013) Release of leukotriene B4, transforming growth factor-beta1 and microparticles in relation to aortic valve calcification. $\mathrm{J}$ Heart Valve Dis 22: 782-788.

Lallam-Laroye C, Escartin Q, Zlowodzki AS, Barritault D, Caruelle JP, Baroukh B, Saffar JL, Colombier ML (2006) Periodontitis destructions are restored by synthetic glycosaminoglycan mimetic. J Biomed Mater Res A 79: 675-683.

Langsdorf A, Do AT, Kusche-Gullberg M, Emerson CP, Jr., Ai X (2007) Sulfs are regulators of growth factor signaling for satellite cell differentiation and muscle regeneration. Dev Biol 311: 464-477.

Li J, Shworak NW, Simons M (2002) Increased responsiveness of hypoxic endothelial cells to FGF2 is mediated by HIF-1alpha-dependent regulation of enzymes involved in synthesis of heparan sulphate FGF2-binding sites. J Cell Sci 115: 1951-1959.
Lortat-Jacob H (2009) The molecular basis and functional implications of chemokine interactions with heparan sulphate. Curr Opin Struct Biol 19: 543-548.

Luyt CE, Meddahi-Pelle A, Ho-Tin-Noe B, ColliecJouault S, Guezennec J, Louedec L, Prats H, Jacob MP, Osborne-Pellegrin M, Letourneur D, Michel JB (2003) Low-molecular-weight fucoidan promotes therapeutic revascularization in a rat model of critical hindlimb ischaemia. J Pharmacol Exp Ther 305: 24-30.

Mangoni M, Yue X, Morin C, Violot D, Frascogna V, Tao Y, Opolon P, Castaing M, Auperin A, Biti G, Barritault D, Vozenin-Brotons MC, Deutsch E, Bourhis, J (2009) Differential effect triggered by a heparan mimetic of the RGTA family preventing oral mucositis without tumor protection. Int J Radiat Oncol Biol Phys 74: 1242-1250.

Marastoni S, Ligresti G, Lorenzon E, Colombatti A, Mongiat M (2008) Extracellular matrix: a matter of life and death. Connect Tissue Res 49: 203-206.

Matsui Y, Ikesue M, Danzaki K, Morimoto J, Sato M, Tanaka S, Kojima T, Tsutsui H, Uede T (2011) Syndecan-4 prevents cardiac rupture and dysfunction after myocardial infarction. Circ Res 108: 1328-1339.

Meddahi A, Lemdjabar H, Caruelle JP, Barritault D, Hornebeck W (1995) Inhibition by dextran derivatives of FGF-2 plasmin-mediated degradation. Biochimie 77: 703-706.

Meddahi A, Alexakis C, Papy D, Caruelle JP, Barritault D (2002) Heparin-like polymer improved healing of gastric and colic ulceration. J Biomed Mater Res 60: 497-501.

Melo F, Carey DJ, Brandan E (1996) Extracellular matrix is required for skeletal muscle differentiation but not myogenin expression. J Cell Biochem 62: 227-239.

Mikami T, Koyama S, Yabuta Y, Kitagawa H (2012) Chondroitin sulphate is a crucial determinant for skeletal muscle development/regeneration and improvement of muscular dystrophies. J Biol Chem 287: 38531-38542.

Najjam S, Gibbs RV, Gordon MY, Rider CC (1997) The binding of interleukin 2 to heparin revealed by a novel ELISA method. Biochem Soc Trans 25: 3S.

Narita K, Staub J, Chien J, Meyer K, Bauer M, Friedl A, Ramakrishnan S, Shridhar V (2006) HSulf-1 inhibits angiogenesis and tumorigenesis in vivo. Cancer Res 66: 6025-6032.

Negroni E, Henault E, Chevalier F, Gilbert-Sirieix M, Van Kuppevelt TH, Papy-Garcia D, Uzan G, Albanese P (2014) Glycosaminoglycan modifications in Duchenne muscular dystrophy: specific remodeling of chondroitin sulphate/dermatan sulphate. J Neuropathol Exp Neurol 73: 789-97.

Ornitz DM, Yayon A, Flanagan JG, Svahn CM, Levi E, Leder P (1992) Heparin is required for cell-free binding of basic fibroblast growth factor to a soluble receptor and for mitogenesis in whole cells. Mol Cell Biol 12: 240-247.

Osses N, Brandan E (2002) ECM is required for skeletal muscle differentiation independently of muscle regulatory factor expression. Am J Physiol 282: C383-394.

Papy-Garcia D, Barbier-Chassefiere V, Rouet V, Kerros ME, Klochendler C, Tournaire MC, Barritault D, Caruelle JP, Petit E (2005) Nondegradative sulphation of polysaccharides. Synthesis and structure characterization 
of biologically active heparan sulphate mimetics. Macromolecules 38: 4647-4654.

Rabbany SY, Heissig B, Hattori K, Rafii S (2003) Molecular pathways regulating mobilization of marrowderived stem cells for tissue revascularization. Trends Mol Med 9: 109-117.

Raval Z, Losordo DW (2013) Cell therapy of peripheral arterial disease: from experimental findings to clinical trials. Circ Res 112: 1288-1302.

Rouet V, Hamma-Kourbali Y, Petit E, Panagopoulou P, Katsoris P, Barritault D, Caruelle JP, Courty J (2005) A synthetic glycosaminoglycan mimetic binds vascular endothelial growth factor and modulates angiogenesis. J Biol Chem 280: 32792-32800.

Rouet V, Meddahi-Pelle A, Miao HQ, Vlodavsky I, Caruelle JP, Barritault D (2006) Heparin-like synthetic polymers, named RGTAs, mimic biological effects of heparin in vitro. J Biomed Mater Res A 78: 792-797.

Schumann K, Lammermann T, Bruckner M, Legler DF, Polleux J, Spatz JP, Schuler G, Forster R, Lutz MB, Sorokin L, Sixt M (2010) Immobilized chemokine fields and soluble chemokine gradients cooperatively shape migration patterns of dendritic cells. Immunity 32: 703713.

Sobieszczyk P, Eisenhauer A (2013) Management of patients after endovascular interventions for peripheral artery disease. Circulation 128: 749-757.

Stern R, Asari AA, Sugahara KN (2006) Hyaluronan fragments: an information-rich system. Eur J Cell Biol 85: 699-715.

Suzuki K, Murtuza B, Beauchamp JR, Brand NJ, Barton PJ, Varela-Carver A, Fukushima S, Coppen SR, Partridge TA, Yacoub MH (2004) Role of interleukin-1beta in acute inflammation and graft death after cell transplantation to the heart. Circulation 110: II219-224.

Terrovitis J, Lautamaki R, Bonios M, Fox J, Engles JM, Yu J, Leppo MK, Pomper MG, Wahl RL, Seidel J, Tsui BM, Bengel FM, Abraham MR, Marban E (2009) Noninvasive quantification and optimization of acute cell retention by in vivo positron emission tomography after intramyocardial cardiac-derived stem cell delivery. J Am Coll Cardiol 54: 1619-1626.

Thelin MA, Bartolini B, Axelsson J, Gustafsson R, Tykesson E, Pera E, Oldberg A, Maccarana M, Malmstrom A (2013) Biological functions of iduronic acid in chondroitin/dermatan sulphate. FEBS J 280: 2431-2446.

Toida T, Shima M, Azumaya S, Maruyama T, Toyoda H, Imanari T, Linhardt RJ (1997) Detection of glycosaminoglycans as a copper(II) complex in highperformance liquid chromatography. J Chromatogr A 787: 266-270.

Toyoda H, Yamamoto H, Ogino N, Toida T, Imanari $\mathrm{T}$ (1999) Rapid and sensitive analysis of disaccharide composition in heparin and heparan sulphate by reversedphase ion-pair chromatography on a $2 \mu \mathrm{m}$ porous silica gel column J Chromatogr A 830: 197-201.

Tran TH, Shi X, Zaia J, Ai X (2012) Heparan sulphate 6-O-endosulfatases (Sulfs) coordinate the Wnt signaling pathways to regulate myoblast fusion during skeletal muscle regeneration. J Biol Chem 287: 32651-32664.

Verma S, Kuliszewski MA, Li SH, Szmitko PE, Zucco L, Wang CH, Badiwala MV, Mickle DA, Weisel RD, Fedak PW, Stewart DJ, Kutryk MJ (2004) C-reactive protein attenuates endothelial progenitor cell survival, differentiation, and function: further evidence of a mechanistic link between C-reactive protein and cardiovascular disease. Circulation 109: 2058-2067.

Villena J, Brandan E (2004) Dermatan sulphate exerts an enhanced growth factor response on skeletal muscle satellite cell proliferation and migration. J Cell Physiol 198: $169-178$.

Wang L, Fuster M, Sriramarao P, Esko JD (2005) Endothelial heparan sulphate deficiency impairs L-selectinand chemokine-mediated neutrophil trafficking during inflammatory responses. Nat Immunol 6: 902-910.

Yablonka-Reuveni Z, Seger R, Rivera AJ (1999) Fibroblast growth factor promotes recruitment of skeletal muscle satellite cells in young and old rats. J Histochem Cytochem 47: 23-42.

Yamagata T, Saito H, Habuchi O, Suzuki S (1968) Purification and properties of bacterial chondroitinases and chondrosulfatases. J Biol Chem 243: 1523-1535.

Yamaguchi J, Kusano KF, Masuo O, Kawamoto A, Silver M, Murasawa S, Bosch-Marce M, Masuda H, Losordo DW, Isner JM, Asahara T (2003) Stromal cell-derived factor-1 effects on ex vivo expanded endothelial progenitor cell recruitment for ischaemic neovascularization. Circulation 107: 1322-1328.

Yamauchi H, Desgranges P, Lecerf L, Papy-Garcia D, Tournaire MC, Moczar M, Loisance D, Barritault D (2000) New agents for the treatment of infarcted myocardium. FASEB J 14: 2133-2134.

Zeng L, Hu Q, Wang X, Mansoor A, Lee J, Feygin J, Zhang G, Suntharalingam P, Boozer S, Mhashilkar A, Panetta CJ, Swingen C, Deans R, From AH, Bache RJ, Verfaillie CM, Zhang J (2007) Bioenergetic and functional consequences of bone marrow-derived multipotent progenitor cell transplantation in hearts with postinfarction left ventricular remodeling. Circulation 115: 1866-1875.

Editor's Note: All questions/comments by the reviewers were answered by text changes. Therefore, there is no Discussion with Reviewers section.

Scientific Editor in charge of the paper: Juerg Gasser. 